\title{
A comprehensive review of circRNA: from purification and identification to disease marker potential
}

\author{
Sheng Xu ${ }^{1}$, LuYu Zhou ${ }^{1}$, Murugavel Ponnusamy ${ }^{1}$, LiXia Zhang ${ }^{2}$, YanHan Dong ${ }^{1}$, YanHui Zhang ${ }^{1}$, Qi \\ Wang ${ }^{1}$, Jing Liu ${ }^{1}$, Kun Wang ${ }^{\text {Corresp. } 1}$ \\ ${ }^{1}$ Center for Developmental Cardiology, Institute of Translational Medicine, College of Medicine, Qingdao University, Qingdao, Shandong, China \\ 2 Department of Inspection, The medical faculty of Qingdao University, Qingdao, Shandong, China \\ Corresponding Author: Kun Wang \\ Email address: wangk696@qdu.edu.cn
}

Circular RNA (circRNA) is an endogenous noncoding RNA with a covalently closed cyclic structure. Based on their components, circRNAs are divided into exonic circRNAs, intronic circRNAs and exon-intron circRNAs. CircRNAs have well-conserved sequences and often have high stability due to their resistance to exonucleases. Depending on their sequence, circRNAs are involved in different biological functions, including microRNA sponge activity, modulation of alternative splicing or transcription, interaction with RNA-binding proteins, and rolling translation, and are a derivative of pseudogenes. CircRNAs are involved in the development of a variety of pathological conditions, such as cardiovascular diseases, diabetes, neurological diseases and cancer. Emerging evidence has shown that circRNAs are likely to be new potential clinical diagnostic markers or treatments for many diseases. Here we describe circRNA research methods and biological functions, and discuss the potential relationship between circRNAs and disease progression. 


\section{A comprehensive review of circRNA: from purification 2 and identification to disease marker potential}

3 Sheng $\mathrm{Xu}^{1}$, Lu-Yu Zhou ${ }^{1}$, Ponnusamy $\mathrm{M}^{1}$, Li-Xia Zhang ${ }^{2}$, Yan-Han Dong ${ }^{1}$, Yan-Hui Zhang ${ }^{1}$, Qi Wang ${ }^{1}$, Jing

4 Liu $^{1}$, Kun Wang ${ }^{1 *}$

5

${ }^{1}$ Center for Developmental Cardiology, Institute of Translational Medicine, College of Medicine, Qingdao University, Qingdao 266003, China;

2Department of Inspection, The medical faculty of Qingdao University, Qingdao 266003, China;

* Corresponding Author

Kun Wang ${ }^{1}$

Email address: wangk696@163.com

13

14

15

16

17

18

19

20

21

22

23

24

25

26

27

28

29

30

31

32

33

34

35

\section{Subheadings}

Disease marker potential; methods of detection and characterization 


\begin{abstract}
Circular RNA (circRNA) is an endogenous noncoding RNA with a covalently closed cyclic structure. Based on their components, circRNAs are divided into exonic circRNAs, intronic circRNAs and exon-intron circRNAs. CircRNAs have well-conserved sequences and often have high stability due to their resistance to exonucleases. Depending on their sequence, circRNAs are involved in different biological functions, including microRNA sponge activity, modulation of alternative splicing or transcription, interaction with RNA-binding proteins, and rolling translation, and are a derivative of pseudogenes. CircRNAs are involved in the development of a variety of pathological conditions, such as cardiovascular diseases, diabetes, neurological diseases and cancer. Emerging evidence has shown that circRNAs are likely to be new potential clinical diagnostic markers or treatments for many diseases. Here we describe circRNA research methods and biological functions as well as discusses the potential relationship between circRNAs and disease progression.
\end{abstract}

\title{
1. Introduction
}

Circular RNA (circRNA) was considered as a class of endogenous noncoding RNA (ncRNA) (Wilusz \& Sharp 2013), but it is now considered that circRNA can be translated into functional polypeptides (Legnini et al. 2017; Pamudurti et al. 2017; Yang et al. 2017b; Yang et al. 2018b). Unlike linear ncRNA, circRNA is formed with different combinations of sequences and domains, and it can be divided into three categories, namely exonic circRNA (ecRNA) (Zhang et al. 2014), circular intronic (ciRNA) (Zhang et al. 2013)and exon-intron circRNA (ElciRNA) (Li et al. 2017b)(Table 1 and Fig. 1). Similar to other ncRNAs, the sequence and structure of circRNA determine its biological functions. CircRNA is mainly located in the cytoplasm and is highly stable compared to other ncRNAs (Danan et al. 2012). In addition, recent research has shown that the lengths of mature circRNA dictate the mode of nuclear export (Huang et al. 2018). CircRNA is abundantly expressed and evolutionarily conserved across eukaryotic organisms (Morris \& Mattick 2014; Wang et al. 2014), and it plays critical roles in many diseases, including nervous system disorders, cardiovascular diseases (CVDs), diabetes and cancer (Burd et al. 2010; Wang et al. 2017b). CircRNA governs gene expression through guiding a number of other 
molecules, such as splicing factors, RNA polymerase II (Jeck et al. 2013), nuclear small ribose nucleoprotein (snRNP) (Huang \& Shan 2015; Li et al. 2017b) and miRNAs (Li et al. 2015a). These interactions promote or inhibit the transcription of the corresponding mRNA.

\section{Survey Methodology}

Analysis: Through extensive literature searches, the role of circRNA in diseases and the methods of circRNA detection and characterization were analyzed, indicating the importance of circRNA and its research prospects, including our previous research results combined with other research results.

\section{Biogenesis of CircRNA}

CircRNA does not have terminal structures, such as a 5' end cap and 3' end poly (A) tail, which are covalently closed to form a circular structure (Jeck et al. 2013). Jeck and colleagues proposed two different models of exon circularization. One model is intron-pairing-driven circularization (Fig. 2a), and the other model is lariat-driven circularization (Fig. 2b) (Jeck et al. 2013). In the first mechanism, the two introns that flank the exon or exons of the incipient circRNA have a complementary structure to bind to each other. The pairing of the flanking introns brings the splice sites close to each other, shaping a secondary structure that makes back-splicing possible. In the second mechanism, a pre-mRNA is spliced, and two transcripts are produced as follows: an mRNA from which one or more exons are missing; and a lariat consisting of the skipped exons, which makes the circularization possible. The exon lariat is spliced one more time to generate two other elements, namely a circRNA and an intron lariat. Typically, many lasso structures are formed by introns, but they are degraded by the branching enzyme (Rodriguez-Trelles et al. 2006). In these two typical models of circularization, ALU complementary flanking elements (retrotransposons characterized by the action of the Arthrobacter luteus (Alu) restriction endonuclease) repeated in intronic regions compete with canonical linear-RNA splicing and act as an inevitable accelerator in the formation of circRNA by reverse complementary matches (Ashwal-Fluss et al. 2014; Hansen et al. 2013a; Ivanov et al. 2015; Jeck et al. 2013). DExH-Box Helicase 9 (DHX9) is an RNA helicase that specifically binds to 
92 reverse Alu elements (IRAlu) to guide the formation of circRNA (Aktas et al. 2017). IRAlu has already become a significant basis of analyzing and forecasting the formation mechanism of circRNA (Zhang et al. 2014). In addition, the genomic structure of long exons flanked by long introns harboring inverted repeat elements facilitates RNA circularization (Jeck et al. 2013). Many proteins are involved in circRNA biogenesis. In normal growing cells, NF90/NF110 binds to $A / U$-rich elements (including base paired Alu elements) in the introns flanking many exons that yield circular RNAs, promoting back-splicing events (Li et al. 2017a). HNRNPL promotes circRNA formation via back splicing (Fei et al. 2017). The RNA-binding proteins, such as MBL (muscleblind) (Ashwal-Fluss et al. 2014) and QKI (RNA-binding protein quaking I) (Conn et al. 2015), also participate in the back-splicing process and cyclization of RNA. Interestingly, high levels of $\mathrm{MBL}$ bind to its own pre-mRNA and determine its back-splicing, leading to the inhibition of canonical splicing, decreasing MBL levels and upgrading circMBL (Ashwal-Fluss et al. 2014). Monomeric QKI binds to both ends of intron flanking sites and combines to form cyclic exons by bringing the two cyclic shear sites close (Conn et al. 2015). FUS regulates circRNA biogenesis by binding the introns flanking the back-splicing junctions (Errichelli et al. 2017). CircRNA production is further controlled by FUS (Errichelli et al. 2017) and by multiple hnRNP (heterogeneous nuclear ribonucleoprotein) and SR (serine-arginine) proteins (Fei et al. 2017; Kramer et al. 2015; Liang et al. 2017). In contrast, the RNA-editing enzyme, ADARs (Adenosine deaminases acting on RNA) block circRNA formation by binding to complementary doublestranded areas of flanking introns and abolishing the interaction of double-stranded chains (Ivanov et al. 2015). Recent research has found that inhibition or slowing of pre-mRNA processing mechanisms, such as spliceosomes, leads to profound increases in circRNA production by extending read through to downstream genes and production of circRNA (Liang et al. 2017).

\section{Properties of CircRNA}

CircRNA has several unique features and properties when compared to other linear RNAs and ncRNAs. Most of the unique features are generated from exons, while few others are generated from introns or intron fragments (Cocquerelle et al. 1993). Several circRNAs possess microRNA response elements (MREs), which enable them to interact with miRNAs to govern 
121 target gene expression (Hansen et al. 2013a; Yang et al. 2016). Many circRNAs are derived from

122

123

124

125

pre-mRNA and regulate their own gene expression predominantly at posttranscriptional levels (Salzman et al. 2012). Generally, circRNAs show tissue-specific and/or developmental stagespecific expression patterns similar to those of corresponding linear mRNA targets, and their expression level is >10 times higher than that of the linear mRNA (Jeck et al. 2013; Memczak et al. 2013). CircRNA exists and has been detected in many types of extracellular body fluids, such as saliva, blood and urine (Jeck et al. 2013; Qu et al. 2015). More than 400 circRNAs have been found in human cell-free saliva (CFS) from healthy individuals (Bahn et al. 2015). CircRNAs have evolutionary conserved sequence features across different species (Rybak-Wolf et al. 2015). The covalently closed loop structures lacking 5'-3' polarity and without poly-adenylated tail favor resistance to RNA exonuclease degradation (Suzuki \& Tsukahara 2014). CircRNA plays stable biological roles because the average half-life of circRNA in most species is much longer than its linear counterpart (Bahn et al. 2015; Memczak et al. 2013).

\section{Function of CircRNA}

CircRNA has a variety of functions, including modulation of alternative splicing or transcription, regulating the expression of parental genes, interacting with RNA-binding proteins (RBPs), altering RBP activity, miRNA sponge activity, rolling circle translation and generating pseudogenes.

\section{1 CircRNA Modulates Alternative Splicing or Transcription}

CircRNA participates in the regulation of alternative splicing and transcription, thereby controlling gene expression (Fig. 3a). For example, circMbl is generated from the second exon of the splicing factor MBL, which competes with canonical pre-mRNA splicing, while circMbl and its flanking introns have conserved MBL-binding sites to allow binding to MBL. Interestingly, the alteration of $\mathrm{MBL}$ level significantly affects circMbl formation, and this effect depends on MBLbinding sites in the flanking intronic sequences (Ashwal-Fluss et al. 2014). Studies have shown that several circRNAs are abundantly found in the nucleus where they regulate transcriptional activity by interacting with polymerase II and homeopathic reactions. For instance, ElciRNA interacts with small nuclear ribonuclease proteins (snRNPs) to regulate the transcription of 
149

150

151

152

153

154

155

156

157

158

159

160

161

162

parental genes in a homeopathic manner (Chen 2016). Li et al. found that circRNA-ITCH interacts with miR-7, miR-17 and miR-214 as well as upregulates the expression of ITCH (Li et al. 2015a). During embryogenesis, sisR-4 promotes transcription of its host gene by activating an enhancer present in the intron where sisR-4 is encoded, which is essential for development (Tay \& Pek 2017). HNRNPL directly regulates the alternative splicing of RNAs, including encoding the androgen receptor, the key lineage-specific prostate cancer oncogene (Fei et al. 2017).

\section{2 CircRNA Interacts with RBPs}

Apart from miRNA regulation, circRNA can sequester RBPs and thus control the intracellular localization and transport of RBPs and associated mRNAs (Hentze \& Preiss 2013; Jeck \& Sharpless 2014) (Fig. 3b). Some circRNAs combine with RBPs and ribonucleoprotein complexes, thereby inhibiting their activity. However, circRNA functions as stores of RBPs and ribonucleoprotein complexes. EcRNA acts as a scaffold by specifically binding to protein molecules to provide an interaction platform for RNA-binding proteins, RNA and DNA. For example, in HEK293 cells, CDR1as contains a region near perfectly complementary to miR-671, which causes the circRNA to be endonucleolytically cleaved by argonaute 2 (AGO2) in a miR671dependent manner (Hansen et al. 2011). CDR1as is derived from an antisense long noncoding RNA (Barrett et al. 2017) and is expressed several orders of magnitude higher than cerebellar degeneration-related protein 1 (CDR1) gene from the opposite strand (Hansen et al. 2011; Piwecka et al. 2017). Chen et al. found that there are cellular differential mechanisms in the recognition of internal and external circRNAs as follows: external circRNA induces activation of RIG-I-mediated cellular autoimmune effector pathways, and endogenous circRNA does not induce this pathway due to binding of RBPs (Chen et al. 2017d).

\section{3 CircRNA as MiRNA Sponge}

CircRNAs act as competing endogenous RNAs (ceRNAs) that contain shared MREs by which they sequester miRNAs and prevent their interactions with target mRNAs (Fig. 3c). Systematically validated circRNAs, such as ciRS-7 (CDR1as) (Hansen et al. 2013a; Memczak et al. 2013) and Sry circRNA (circSry) (Hansen et al. 2013a; Zhao \& Shen 2015), are produced from the mRNAs of cerebellar degeneration associated protein 1 (CDR1) and dysregulated rat testis SRY, 
177 respectively. During the embryonic developmental process in zebrafish, the expression of 178 CDRlas reduces brain volume, thereby hampering brain development. However, exogenous 179 delivery of miR-7 reverses the brain volume reduction and reinstates normal brain

development, indicating that CDRlas blocks miR-7 by sponging functions (Hansen et al. 2013a; Hansen et al. 2013b). New research has found that the CDR1as sequence overlaps the IncRNA LINC00632 sequence (Barrett et al. 2017). In general, there are only several circRNAs containing enough miRNA-binding sites to function as strong sponges, and other circRNAs are exceptional cases (Chen 2016; Tay \& Pek 2017). Knockdown of circHIPK2 expression significantly inhibits astrocyte activation via regulation of autophagy and endoplasmic reticulum (ER) stress through targeting MIR124-2HG and SIGMAR1 (Huang et al. 2017). CircHECW2 plays a role in the epithelial-mesenchymal transition (EMT) pathway by competitively inhibiting miR-30D, which releases ATG5, thereby promoting the Notch1 signaling pathway (Yang et al. 2018a).

\section{4 Rolling Circle Translation}

In eukaryotic cells, cyclic mRNA can be translated by typical translation machineries because it contains an internal ribosome entry site (IRES) sequence, and it can bind directly to the ribosome (Thompson 2012) (Fig. 3d). In prokaryotic cells, such as E. coli, circRNA contains a well-conserved infinite open reading frame (ORF) system, which enables the translation of circularized RNA (Abe et al. 2015). In eukaryotic systems, some circRNAs have binding sites for ribosomal 405 subunits, thus initiating translation, which has been demonstrated both in vivo and in vitro studies (Holdt et al. 2017). In an E. coli system, circRNA with green fluorescent protein (GFP) inserted in the open reading frame can successfully translate GFP (Wang \& Wang 2015). Interestingly, circRNA also drives protein translation by methylation of adenosine N6 (m6A) (Yang et al. 2017b). Protein translated by circRNA can act synergistically with the protein expression products of the parent gene and function together. For example, circ-FBXW7 translates a new protein that inhibits glioma (Yang et al. 2018b). Circ-ZNF609 directly translates into proteins that participate in muscle formation (Legnini et al. 2017). In prokaryotic cells, proteins are generated from circRNA by means of rolling circle amplification (RCA) analogous to a polymerase reaction in the eukaryotic translation system, which reveals that there is no need for multiple binding of translational machinery to the RNA template (Rodriguez-Trelles et al. 
206 2006). The circular amplification not only produces long and repetitive peptide sequences but

207 also increases the productivity of the linear counterpart (Thompson 2012).

208

209

210

211

212

213

214

215

216

217

218

219

220

221

222

223

224

225

226

227

228

229

230

231

232

\section{5 Generate Pseudogenes}

Studies have shown that stable circulatory molecules can be reverse transcribed and integrated into the genome to form circRNA-derived pseudogenes (Dong et al. 2016) (Fig. 3e). Bioinformatics analysis of the mouse genome using computational pipeline (CIRCpseudo) found that at least 33 pseudogenes are possibly derived from the same circRNA at the ring finger and WD repeat domain 2 (RFWD2) locus (circRFWD2) and that 9 of the pseudogenes are from exons (exons 2 to 4 or 5 ) of circRFWD2. It is well documented that pseudogenes play an important role in cell differentiation and in cancer progression (Kalyana-Sundaram et al. 2012).

\section{Methods of CircRNA Detection and Characterization}

\section{1 Preliminary Purification and Identification}

\section{1. 1 Molecular biology method}

The loop structure of circRNA has high stability compared to linear RNA, and it is resistance to enzyme digestion (You \& Conrad 2016). Therefore, an enzymatic digestion method can be used for the preliminary purification and identification of circRNA (Jeck \& Sharpless 2014).

First, the processing of extracted RNA with exonucleases, such as RNase R, nicotinic acid phosphatase and 5' end exonuclease, destroys most linear RNA, but circRNA remains intact due to no open ends in circRNA for these enzyme reactions. A circRNA-specific divergent primer can be used to amplify abundant circRNA in which linear RNAs do not amplify (Jeck \& Sharpless 2014; Suzuki et al. 2006). Second, the migration velocity of circRNA is slower than that of long linear RNA due to lack of polarity at the end. Particularly, circRNA migration is much slower than RNA from homologous gene transcription in weak crosslinked gels, and this difference helps to detect circRNAs easily through Northern blot analysis (Tabak et al. 1988). Third, the fluorescence in situ hybridization technique can locate circRNA at a subcellular level (Li et al. 2017b; Zhang et al. 2013). As circRNA does not have a poly (A) structure, the traditional oligo dT 
233

234

235

236

237

238

239

240

241

242

243

244

245

246

247

248

249

250

251

252

253

254

255

256

257

258

259

260

enrichment method using a Ribo-Zero kit to remove rRNA is not effective. The removal of linear RNA using RNase $R$ is the most effective step for the enrichment of circRNA and generating a circRNA library (Ebbesen et al. 2016; Jeck \& Sharpless 2014).

\section{1. 2 High-throughput sequencing}

The traditional RNA-Seq technique does not distinguish circRNAs from linear RNAs (You \& Conrad 2016). As a result, improvements have been made to detect and validate circRNA. First, as the intergenic exon rearrangement has different forms, generation of divergent primers with boundary combinations can form circRNA candidate sequence, which can be used to compare to sequencing data (Salzman et al. 2013). Second, bioinformatics analysis of whole genome sequence and assessment of sequence data through different sequence alignment algorithm can be used to identify circRNAs (Jeck et al. 2013). Third, templates designed with multiple sequence splice joints can directly detect circRNAs from cDNA sequence (Hoffmann et al. 2014).

Currently, many algorithms are available for the prediction and study of circRNAs, including Acfs (You \& Conrad 2016), FUCHS (Metge et al. 2017) and CIRI2 (Gao et al. 2017). Acfs allows accurate and fast identification of circRNA, and it also determines the abundance of circRNAs from single- and paired-ended RNA-Seq data. Acfs is well suitable for a wide spectrum of applications, including characterizing the landscape of circRNA from a variety of organisms. The FUCHS system is based on long sequencing reads (> $150 \mathrm{bp} / \mathrm{reads}$ ), which detects circRNA within the variable shear and provides other information for more accurate interpretation. CIRI2 uses the maximum likelihood estimate based on multiple seed matches to identify reverse splice junctions, and it filters out false positives and mapping errors derived from the repetitive sequence. CIRI2 has a significant balance of sensitivity, reliability, duration and RAM usage (Ebbesen et al. 2016; Jeck \& Sharpless 2014).

\section{1.3 Gene chip}

The human genome array, U133plus2.0 tool, can detect mRNA but cannot detect ring RNA because the probe is designed for linear RNA (Lu et al. 2017). Therefore, the human genome array cannot effectively distinguish circRNA and linear RNA when a normal probe is used. However, if the probe is designed based on the reverse splice site of the circRNA, this array tool 
261 can specifically detect circRNA because there is no reverse splice site sequence in linear RNA, 262 thus effectively distinguishing circRNA and mRNA (Li et al. 2018).

263

264

265

266

267

268

269

270

271

272

273

274

275

276

277

278

279

280

281

282 283

\section{1. 4 Primer Design}

Recently, the field of circRNA research is gaining more attention because circRNAs contribute to many physiological and pathological processes. Unlike conventional PCR primers, the design of circRNA primers should consider certain criteria. For the detection of ecRNA, primers should be designed for the cross-cut site (back-splice). In the case of ciRNA, primers targeting cross-cleavable sites should be used. Primers can also be designed around intron regions. Moreover, the length of the amplified product should not be more than $100 \mathrm{bp}$. Sequence position transformation is also important (Panda \& Gorospe 2018). The differences in the selection of primers for linear RNA and circRNA are listed in Fig. 4.

The actual amplification effect after primer design needs to be experimentally determined. If the quantification of circRNA is performed by qPCR, the length of amplification should be identified according to the experimental requirements of qPCR. Thus, qPCR remains the most widely used technique to assess the expression level of circRNA.

\section{2 CircRNA Research Database}

In recent years, increasing numbers of circRNA research tools with different aspects and improved functional analysis have been generated. The currently available online databases for the detection and characterization of circRNA, which contain GenBank annotations or circRNA from published articles, are presented here. Each database analyzes circRNA with different characteristic features for detection, and each database provides abundant information for circRNAs. There are several free online databases available for circRNA research as shown in Table 2.

\section{CircRNA as a disease marker in disease progression}

The best-known circRNA, CDR1as, is the inhibitor of miR-7, and it is the critical ncRNA known to be involved in various diseases, including cancer, neurodegenerative diseases, 
287

288

289

290

291

292

293

294

295

296

297

298

299

300

301

302

303

304

305

306

307

308

309

310

311

312

313

314

diabetes, and atherosclerosis (Peng et al. 2015). In addition more functions of circRNAs being revealed, the underlying relationships between circRNAs and various diseases have been rapidly elucidated. The great specificity and conservation of circRNAs in various tissues add a further dimension to the discovery of these disease biomarkers. CircRNAs involved in diseases are listed in Table 3.

\subsection{CircRNA in Cardiovascular Diseases (CVD)}

CVD poses an increasing threat to human health. According to a report from the World Health Organization (WHO), nearly 17.5 million people die of CVD each year (Mendis et al. 2015). CircRNA is highly specific and is exclusively expressed in different tissues, including vascular and heart tissue (Fan et al. 2017).

\subsubsection{Pathological hypertrophy and heart failure (HF)}

MiR-223 is an endogenous regulator of hypertrophy in cardiomyocytes, which can induce cardiac hypertrophy and heart failure (Wang et al. 2015b). In cardiac hypertrophy, ARC (apoptosis repressor with CARD domain) is a miR-223 downstream target (Wang et al. 2016). The heart-related circRNA (HRCR) can function as an endogenous miR-223 sponge to inhibit miR-223 activity, subsequently increasing the expression of ARC (Wang et al. 2016). However, the expression of HRCR is decreased during cardiac hypertrophy and heart failure. Thus, it is speculated that increased expression of HRCR attenuates the development of cardiac hypertrophy and heart failure, and it may be an attractive therapeutic target for cardiovascular disorders associated with pathological hypertrophy (Wang et al. 2016).

\subsubsection{Atherosclerosis}

Circular ANRIL RNA (circular antisense noncoding RNA in the INK4 locus, CANRIL) is an antisense transcript from the INK4A/ARF (cyclin-dependent kinase 4 inhibitor, INK4a; alternative reading frame, ARF) locus (Salzman et al. 2013), which inhibits the expression of INK4/ARF (Burd et al. 2010). Another research group found that cANRIL prevents rRNA prebinding and exonuclease-mediated rRNA maturation by binding to the C-terminal lysine-rich domain of PES1, inducing an increase in the expression and activity of p53 and subsequent decrease in apoptosis. This pathway inhibits atherosclerosis by eliminating hyperproliferative 
315 cell types in atherosclerotic plaques, indicating that cANRIL may be associated with the 316 prevention or treatment of atherosclerosis (Holdt et al. 2016).

317 6.1.3 Cardiac senescence

318 CircFoxo3 is generated from Foxo3, a member of the forkhead family of transcription 319 factors that is highly expressed in aged heart samples from elder patients. The expression of 320 circFoxo3 is highly correlative with markers of cellular senescence (Du et al. 2016 a). 321 Experimental studies have found that cells expressing high levels of circFoxo3 are unable to transition to $S$ phase, revealing that circFoxo3 represses cell cycle progression and cell proliferation (Du et al. 2016b). CircFoxo3 is mainly distributed in the cytoplasm where it interacts with several transcription factors (E2F1, FAK, and HIF1a) and antisenescence proteins, such as ID-1, thus preventing their nuclear entry. In fact, the nuclear entry of FAK and HIF1a is essential for their antisenescence role. Thus, circFoxo3 repress their antiaging effects. In addition, circFoxo3 also positively correlates with cellular senescence (Du et al. 2016a). Together, these studies suggest that circRNA originating from FOXO genes may be a promising target for repositioning of ID-1, E2F1, FAK and HIF1a from the cytoplasm to nucleus, ultimately attenuating cellular senescence in aging hearts (Du et al. 2016a).

\subsubsection{Myocardial Infarction (MI)}

MI is a fatal disease worldwide (Mozaffarian et al. 2015). Due to the lack of available biomarkers, MI cannot be predicted effectively (Vausort et al. 2016). To date, some studies have made significant progress in solving this issue.

Wang et al. found that MFACR (mitochondrial fission and apoptosis-related circRNA) plays a protective role in the heart through attenuating mitochondrial fission in cardiomyocytes by directly targeting miR-652-3p and increasing the expression of its target, MTP18, which promotes cell survival in cardiomyocytes. Thus, MFACR-dependent inhibition of miR-652-3p increases MTP18 and mitochondrial fission, which results in a reduction in cardiomyocyte apoptosis and extension of MI injury (Wang et al. 2017a). Cdr1as play detrimental roles in MI by acting as a miR-7 sponge and inhibiting its activity (Geng et al. 2016; Memczak et al. 2013; Xu et al. 2017a). It is well documented that miR-7a/b plays a protective role through negatively regulating the expression of PARP and decreasing apoptosis in myocardial cells (Fan et al. 2017; 
344

345

346

347

348

349

350

351

352

353

354

355

356

357

358

359

360

361

362

363

364

365

366

367

368

369

370

371

372

Zhao et al. 2009). SPI and PARP (poly ADP-ribose polymerase) play proapoptotic roles during MI development (Li et al. 2014a; Read et al. 2014). Hypoxia-induced increases in SP1 and PARP expression cause apoptotic cell death, and SP1 and PARP are target genes of miR-7, which can decrease cell apoptosis (Geng et al. 2016; Li et al. 2014a; Read et al. 2014). Collectively, the ciRS-7-miR-7-PARP/SP1 axis may offer new biomarkers for the diagnosis of MI, while additional diagnostic markers remain to be discovered (Fan et al. 2017).

\subsection{CircRNA in Neurodegenerative Diseases}

There are thousands of circRNAs expressed in brain tissue (Rybak-Wolf et al. 2015; You et al. 2015). As the central nervous system ages, age-related circRNAs accumulate in the brain and have been identified as promising indicators of aging (Kumar et al. 2017). This section focuses on aging diseases, such as nerve injury, Alzheimer's disease (AD) and Parkinson's disease.

In hippocampal neural cells (HT22), Lin et al. (Lin et al. 2016) found that oxygen-glucose deprivation/reoxygenation (OGD/R) injury significantly regulates the expression of 15 circRNAs compared to normal cells, suggesting the involvement of circRNA in nerve injury. Moreover, CDRlas plays a protective role by inhibiting miR-7, which directly regulates the expression of asynuclein and ubiquitin protein A. Importantly, a-synuclein and ubiquitin protein $\mathrm{A}$ are associated with the occurrence of AD (Lukiw 2013) and Parkinson's disease (Hancock 2014). However, the disturbance of the miRNA-circRNA system in the hippocampal CAl region of disseminated $A D$ causes the adsorption of miR-7, leading to increased expression of ubiquitin protein $A$ in the human central nervous system (Zhao et al. 2016). In lead-induced neuronal apoptosis, circRar1 directly inhibits miR-671, resulting in suppression of Akt2 and increased expression of caspase-8 and other apoptosis-related proteins (Nan et al. 2017). Currently, the function of circRNA in the nervous system is largely unclear, and the potential of circRNA as a biomarker for neurodegenerative disorder requires further study (Kumar et al. 2017).

\subsection{Diabetes}

CDRlas plays an essential role in islet cell function and insulin secretion (Xu et al. 2015). Thus, CDRlas may gain importance in the diagnosis and treatment of diabetes mellitus. It is well known that the impairment of islet $\beta$-cell function leads to absolute or relative insulin deficiency (insulin resistance), which increases blood sugar level and diabetes (Kim et al. 2017; 
$373 \mathrm{Xu}$ et al. 2015). MiR-7 negatively regulates islet $\beta$-cell proliferation. MiR-7 overexpression 374 damages the dedifferentiation ability of $\beta$ cells, leading to downregulation of insulin secretion 375 and ultimately diabetes. MiR-7 targets multiple components of the mammalian (mTOR) 376 signaling pathway, which are involved in pancreatic $\beta$ cell proliferation. Silencing of miR-7 377 expression in $\beta$ cells increases their proliferative activity, indicating that miR-7 affects pancreatic $\beta$-cell renewal and is associated with diabetes mellitus. Together, these findings reveal that CDR1as/miR-7 may be a potential therapeutic target for treating and managing diabetes (Wang et al. 2013).

\subsection{CircRNA in Cancer}

Accumulating evidence has shown that circRNAs affect the invasive characteristics of tumors in various ways, including competition with miRNAs, translation into proteins, activity as miRNA reservoirs, and formation of fusion circRNAs (f-circRNAs) (Han et al. 2017; Memczak et al. 2013). Genomic alterations, particularly aberrant chromosomal translocations, are responsible for the onset of many types of cancers and solid tumors (Jeck et al. 2013). FcircRNA, which is produced from transcribed exons of translocated chromosomes, promotes carcinogenesis by increasing cell viability and resistance to therapy. Abnormal f-circRNA is functionally related to cancer progression in many types of malignancies (Guarnerio et al. 2016). The specific roles of circRNAs in various tumors are described in the following sections.

\subsubsection{CircRNA in Gastric Cancer (GC)}

$\mathrm{GC}$ is the fourth most common gastrointestinal malignant neoplasm and is the third leading cause of cancer-related deaths worldwide (Doi et al. 2015). Numerous circRNAs are abnormally expressed in GC. Increased expression of Hsa-circ-002059 is significantly associated with the tumor stage of GC (Li et al. 2015c). CircRNA_100269 suppresses gastric tumor cell growth by targeting miR-630. However, circRNA_100269 expression is downregulated during GC and can be used as a biomarker to predict cancer recurrence (Zhang et al. 2017). The expression levels of hsa_circ_0003159 (Tian et al. 2017), hsa_circ_0001895 (Shao et al. 2017) and hsa_circ_0000190 (Chen et al. 2017c) are down-regulated in GC. Another research group has 400 found that the expression of circPVT1 is often upregulated in GC tissue (Chen et al. 2017a). Sui 
402 MALAT1, is regulated through different mechanisms of circRNA-miRNA-mRNA interactions (Sui 403 et al. 2017). Together, all studies have shown that circRNA plays a crucial role during gastric 404 cancer development and that circRNA expression levels can be used as potential biomarkers for 405 clinical prognosis prediction, sensitivity and specificity (Li et al. 2015b).

406 6.4.2 Colorectal Cancer (CRC)

407 In CRC, the downregulated hsa_circ_001988 is associated with differentiation and 408 perineural invasion (Wang et al. 2015a). Perineural invasion is a predictor of prognosis in 409 colorectal cancer, and it is negatively correlated with survival time and local recurrence in 410 colorectal cancer patients (Peng et al. 2011). These results suggest that circRNAs may be 411 potential candidates for therapeutics and biomarkers for CRC (Wang et al. 2015a). Evidence has 412 shown that circRNA is related to $\mathrm{CRC}$. Cir-ITCH is also downregulated in CRC, exhibiting an anticancer effect by binding to miR-7 and miR-20a (Huang et al. 2015). Circ_001569 directly 414 inhibits the regulatory activity of miR-145, thereby upregulating the expression of its targets, such as E2F5, BAG4 and FMNL2, which are involved in tumor proliferation and invasion in CRC 416 (Xie et al. 2016). CircCCDC66 regulates a subset of oncogenes, which control multiple 417 pathological processes, including cell proliferation, migration, invasion, and anchorage418 independent growth, in CRC (Hsiao et al. 2017). In addition, other circRNAs, such as 419 hsa_circ_000984 (Xu et al. 2017b) and hsa_circ_001988 (Wang et al. 2015a), are also 420 abnormally expressed in CRC.

\section{6.4.3 Esophageal Squamous Cell Carcinoma (ESCC)}

422 ESCC is one of the most prevalent and deadly types of cancers, and the prognosis of ESCC 423 remains poor (Xia et al. 2016b). In ESCC, has_circ_0067934 is upregulated and accelerates 424 malignant cell proliferation (Xia et al. 2016b). The expression of Cir-ITCH inhibits ESCC 425 proliferation by suppressing the $W n t / \beta$-catenin pathway through sponging miRNAs, such as $426 \mathrm{miCH}-7$, miR-17 and miR-214. It is well known that ITCH mediates degradation of activated 427 Dvl2, which is a key component of the Wnt pathway. However, the downregulation of Cir-ITH in 428 ESCC releases the brakes on the Wnt pathway by enhancing the expression of oncogenic miCH429 7, miR-17 and miR-214, consequently leading to uncontrolled proliferation of ESCC (Li et al. 430 2015a). Sun et al. constructed a circRNA-miRNA interaction network, in which circRNA9927- 
431 NBEAL1 represents the largest node. These findings indicate that some circRNAs may be novel 432 potential biomarkers and therapeutic targets of ESCC (Xia et al. 2016b).

433 6.4.4 Hepatocellular Carcinoma (HCC)

434 Hepatocellular carcinoma ( $\mathrm{HCC}$ ) is the second leading cause of cancer-related deaths across 435 the world and is particularly prevalent in less developed countries [104]. Increasing evidence 436 has suggested that circRNAs may play a key role in the development of HCC. The ZKSCAN1 gene 437 and its related circRNA (circZKSCAN1) inhibit HCC cell growth, migration, and invasion by

438

439

440

441

442

443

444

445

446

447

448

449

450

451

452

453

454

455

456

457

458 blocking several signaling pathways (Yao et al. 2017). MiR-7 is a tumor-suppressing ncRNA, which attenuates HCC proliferation, and it decreases the risk of microvascular invasion (MVI) by suppressing the expression of its target gene, PIK3CD, and p70S6K (Xu et al. 2017a). However, miR-7 activity is counteracted by the overexpression of CDRlas, which adsorbs miR-7 (Xu et al. 2017a). Similarly, hsa_circ_0005075 participates in cell adhesion during HCC development and is considered as a biomarker for HCC (Shang et al. 2016). In contrast, the expression levels of tumor suppressive circRNA, such as hsa_circ_0004018 (Fu et al. 2017), hsa_circ_0001649 (Qin et al. 2016) and CircARSP91 (Shi et al. 2017), are significantly downregulated in HCC. CircRNA can interact with transcription factors. Twist is a critical epithelial-mesenchymal transition (EMT)-inducing transcription factor that increases expression of Vimentin, and circ-10720 knockdown counteracts the tumor-promoting activity of Twist1 in vitro (Meng et al. 2018). More importantly, circ-ITCH not only has prognostic significance but can also be used as a predictive biomarker for HCC (Guo et al. 2017).

\subsubsection{Cervical Cancer}

Cervical cancer is one of the most common death-causing malignancies in women worldwide. Focal adhesion kinase (FAK), which is a key regulator of growth factor receptor- and integrin-mediated signal pathways, promotes the proliferation, invasion and migration of cervical cancer cells, and it exacerbates the progression of the disease (Lee et al. 2015). In HeLa and C33A cells, the increased level of CDRlas promotes FAK expression by inhibiting miR-7, which targets FAK and acts as a tumor suppressor in cervical cancer cells. This finding indicates that there is a relationship between CDRlas and oncogenic transcription factors in cervical 
459 cancer. Thus, the targeted therapy of CDRlas regulatory networks would provide a new 460 approach for the diagnosis and treatment of cervical cancer (Lee et al. 2015).

461 6.4.6 Breast Cancer (BC)

$462 B C$, the most frequently diagnosed cancer in women around the world, has been the focus 463 of major advances in the last few decades (Doi et al. 2015). Many circRNAs are differentially 464 expressed in BC and participate in cancer-related pathways mainly by sequestering tumor 465 suppressive miRNAs (Lu et al. 2017). Hippo signaling promotes BC progression by upregulating 466 the expression of AMOTL1 and favoring metastasis (Couderc et al. 2016). Interestingly, the 467 expression of circ-Amotl1 does not alter Amotl1 mRNA or protein levels. However, circ-Amotl1 interacts with c-myc and translocates to the nucleus, revealing that the functions of circ-Amotl1 are different from the conventional miRNA sponging activity of circRNA in BC cells (Yang et al. 2017a). Tumor metastasis is one of the most important factors for tumor death. Forkhead box C1 (FOXC1), the target of miR-3607, is downregulated in circlRAK3-silenced cells, and it mediates circlRAK3-induced BC cell migration (Wu et al. 2018a). 6.5 Other diseases

Some other diseases also show a connection with circRNAs. Hsa_circ_0005105 promotes extracellular matrix $(E C M)$ degradation by regulating the expression of the miR-26a target, NAMPT, in osteoarthritis (OA) (Wu et al. 2017). Hsa_circRNA_103636 is easily detectable in blood samples, and the expression pattern of hsa_circRNA_103636 is altered in major depressive disorders (MDDs) (Cui et al. 2016). CircHECTD1 mediates silica-induced macrophage activation via HECTD1/ZC3H12A-dependent ubiquitination in Silicosis (Zhou et al. 2018). In bladder cancer, circTCF25 downregulates miR-103a-3p and miR-107 as well as upregulates cyclin-dependent kinases 6 (CDK6), suggesting that circTCF25 is a new biomarker (Zhong et al. 482 2016).

Cancer-related circRNAs with their corresponding miRNAs form a circRNA-miRNA-mRNA axis that regulates the expression of cancer-related proteins (Sui et al. 2017). Furthermore, the new expression of circRNAs in tumor cells, tissue-specificity, diversity, and high stability identify circRNAs as useful biological markers of cancer, thus improving the accuracy and specificity of 487 diagnostic biomarkers (Zhong et al. 2016). 


\subsection{CircRNA as a disease marker potential}

Currently available reports clearly show that alterations in the expression of circRNA play important roles in the development of various pathological conditions. CircRNA is emerging as a novel biomarker due to its conservation, abundance, cell type-specific expression, tissuespecific expression, and roles in disease progression (Meng et al. 2017). HRCR attenuates the pathogenesis of cardiac diseases and has the potential to become a therapeutic target (Wang et al. 2016). CircFoxo3 may be a promising target of cellular senescence in aging heart (Du et al. 2016a).

Researchers have provided evidence that ciRS-7 has the potential as a biomarker for neurodegenerative disorder (Lukiw 2013), diabetes (Wang et al. 2013), or MI (Lin et al. 2018). CircRNAs regulate the expression of cancer-related proteins in various types of cancer, including GC (Li et al. 2015c; Shao et al. 2017), CRC (Wang et al. 2015a), ESCC (Xia et al. 2016b), HCC (Yao et al. 2017), and BC (Lu et al. 2017), through the circRNA-miRNA-mRNA axis, which represents their potential as diagnostic markers, prognostic indicators, therapeutic targets and even drug prospects in cancer.

\section{Conclusion and Future Directions}

CircRNAs have conserved sequences, tissue specificity, high stability and high abundance, thereby making them potential markers for disease screening and treatment (Westholm et al. 2014). The rapid development of high-throughput sequencing techniques and bioinformatics analyses suggest that circRNAs are likely to become new efficient targets in the clinical settings for the detection and treatment of diseases, such as diabetes, cancer, cardiovascular disease and neurological diseases. circRNAs can function as miRNA sponges (Hansen et al. 2013a) and regulate multiple signaling pathways in CVDs (Fan et al. 2017), different types of cancers (Lu et al. 2017; Meng et al. 2018; Yao et al. 2017), neurodegenerative diseases (Kumar et al. 2017) and diabetes (Zhao et al. 2017). However, further studies are needed to reveal the complete biological functions of circRNA in terms of both physiological and pathological processes to promote the application of circRNA in future clinical use.

Despite rapid advances in the detection and characterization of circRNAs, the knowledge of circRNA functions is still at an early stage, which is one of the major drawbacks for the potential 
517 use of circRNAs for therapeutic or diagnostic purposes. New methods, such as chip technology,

518 can be used to screen possible disease-related circRNAs in cell or experimental animal models,

519 which will increase our knowledge about the role of circRNAs in the occurrence and 520 development of pathological disorders. In addition to broadening functional aspects of circRNA, 521 the following unknowns should also be addressed: mechanisms of trigger and control of 522 circRNA formation dynamics; the link between the circRNA formation process and the 523 corresponding linear RNA generation; the relationship between different circRNA products 524 from the same gene; and regulatory mechanism of circRNA generation. The identification and 525 characterization of specific circRNA-interacting molecules are important to provide information 526 for most of these unknowns. In addition, the naming of circRNA has not yet been unified, and 527 the mechanisms of circRNA in many diseases remain unclear. By solving these unknowns, circRNA may be a promising diagnostic tool and efficient therapeutic target for treatment of various pathological disorders.

Abe N, Matsumoto K, Nishihara M, Nakano Y, Shibata A, Maruyama H, Shuto S, Matsuda A, Yoshida M, Ito $\mathrm{Y}$, and Abe H. 2015. Rolling Circle Translation of Circular RNA in Living Human Cells. Sci Rep 5:16435. 10.1038/srep16435

Aktas T, Avsar Ilik I, Maticzka D, Bhardwaj V, Pessoa Rodrigues C, Mittler G, Manke T, Backofen R, and Akhtar A. 2017. DHX9 suppresses RNA processing defects originating from the Alu invasion of the human genome. Nature 544:115-119. 10.1038/nature21715

Ashwal-Fluss R, Meyer M, Pamudurti NR, Ivanov A, Bartok O, Hanan M, Evantal N, Memczak S, Rajewsky N, and Kadener S. 2014. circRNA biogenesis competes with pre-mRNA splicing. Molecular Cell 56:55-66. 10.1016/j.molcel.2014.08.019

Bahn JH, Zhang Q, Li F, Chan TM, Lin X, Kim Y, Wong DT, and Xiao X. 2015. The landscape of microRNA, Piwi-interacting RNA, and circular RNA in human saliva. Clinical Chemistry 61:221230. 10.1373/clinchem.2014.230433

Barrett SP, Parker KR, Horn C, Mata M, and Salzman J. 2017. ciRS-7 exonic sequence is embedded in a long non-coding RNA locus. PLoS Genetics 13:e1007114. 10.1371/journal.pgen.1007114

Burd CE, Jeck WR, Liu Y, Sanoff HK, Wang Z, and Sharpless NE. 2010. Expression of linear and novel circular forms of an INK4/ARF-associated non-coding RNA correlates with atherosclerosis risk. PLoS Genetics 6:e1001233. 10.1371/journal.pgen.1001233

Chen J, Li Y, Zheng Q, Bao C, He J, Chen B, Lyu D, Zheng B, Xu Y, Long Z, Zhou Y, Zhu H, Wang Y, He $X$, Shi Y, and Huang S. 2017a. Circular RNA profile identifies circPVT1 as a proliferative factor and prognostic marker in gastric cancer. Cancer Letters 388:208-219. 10.1016/j.canlet.2016.12.006 
551 Chen L, Zhang S, Wu J, Cui J, Zhong L, Zeng L, and Ge S. 2017b. circRNA_100290 plays a role in oral

552

553

554

555

556

557

558

559

560

561

562

563

564

565

566

567

568

569

570

571

572

573

574

575

576

577

578

579

580

581

582

583

584

585

586

587

588

589

cancer by functioning as a sponge of the miR-29 family. Oncogene. 10.1038/onc.2017.89

Chen LL. 2016. The biogenesis and emerging roles of circular RNAs. Nature Reviews: Molecular Cell Biology 17:205-211. 10.1038/nrm.2015.32

Chen S, Li T, Zhao Q, Xiao B, and Guo J. 2017c. Using circular RNA hsa_circ_0000190 as a new biomarker in the diagnosis of gastric cancer. Clin Chim Acta 466:167-171. 10.1016/j.cca.2017.01.025

Chen X, Han P, Zhou T, Guo X, Song X, and Li Y. 2016. circRNADb: A comprehensive database for human circular RNAs with protein-coding annotations. Sci Rep 6:34985. 10.1038/srep34985

Chen YG, Kim MV, Chen X, Batista PJ, Aoyama S, Wilusz JE, Iwasaki A, and Chang HY. 2017d. Sensing Self and Foreign Circular RNAs by Intron Identity. Molecular Cell. 10.1016/j.molcel.2017.05.022

Cheng Z, Liu K, Yan Z, Xiang S, and Sun Z. 2015. nc2Cancer: a database for cancer-associated human ncRNAs. Chinese Journal of Bioinformatics.

Cocquerelle C, Mascrez B, Hetuin D, and Bailleul B. 1993. Mis-splicing yields circular RNA molecules. FASEB Journal 7:155-160.

Conn SJ, Pillman KA, Toubia J, Conn VM, Salmanidis M, Phillips CA, Roslan S, Schreiber AW, Gregory PA, and Goodall GJ. 2015. The RNA binding protein quaking regulates formation of circRNAs. Cell 160:1125-1134. 10.1016/j.cell.2015.02.014

Couderc C, Boin A, Fuhrmann L, Vincent-Salomon A, Mandati V, Kieffer Y, Mechta-Grigoriou F, Del Maestro L, Chavrier P, Vallerand D, Brito I, Dubois T, De Koning L, Bouvard D, Louvard D, Gautreau A, and Lallemand D. 2016. AMOTL1 Promotes Breast Cancer Progression and Is Antagonized by Merlin. Neoplasia 18:10-24. 10.1016/j.neo.2015.11.010

Cui X, Niu W, Kong L, He M, Jiang K, Chen S, Zhong A, Li W, Lu J, and Zhang L. 2016. hsa_circRNA_103636: potential novel diagnostic and therapeutic biomarker in Major depressive disorder. Biomark Med 10:943-952. 10.2217/bmm-2016-0130

Danan M, Schwartz S, Edelheit S, and Sorek R. 2012. Transcriptome-wide discovery of circular RNAs in Archaea. Nucleic Acids Research 40:3131-3142. 10.1093/nar/gkr1009

Doi A, Kita A, Kanda Y, Uno T, Asami K, Satoh R, Nakano K, and Sugiura R. 2015. Geranylgeranyltransferase Cwg2-Rho4/Rho5 module is implicated in the Pmk1 MAP kinasemediated cell wall integrity pathway in fission yeast. Genes to Cells 20:310-323. 10.1111/gtc.12222

Dong R, Zhang XO, Zhang Y, Ma XK, Chen LL, and Yang L. 2016. CircRNA-derived pseudogenes. Cell Research 26:747-750. 10.1038/cr.2016.42

Du WW, Yang W, Chen Y, Wu ZK, Foster FS, Yang Z, Li X, and Yang BB. 2016a. Foxo3 circular RNA promotes cardiac senescence by modulating multiple factors associated with stress and senescence responses. Eur Heart J. 10.1093/eurheartj/ehw001

Du WW, Yang W, Liu E, Yang Z, Dhaliwal P, and Yang BB. 2016b. Foxo3 circular RNA retards cell cycle progression via forming ternary complexes with p21 and CDK2. Nucleic Acids Research 44:28462858. 10.1093/nar/gkw027

Dudekula DB, Panda AC, Grammatikakis I, De S, Abdelmohsen K, and Gorospe M. 2016. CircInteractome: A web tool for exploring circular RNAs and their interacting proteins and microRNAs. RNA Biol

PeerJ reviewing PDF | (2018:03:27193:3:1:REVIEW 18 Jul 2018) 
590

591

592

593

594

595

596

597

598

599

600

601

602

603

604

605

606

607

608

609

610

611

612

613

614

615

616

617

618

619

620

621

622

623

624

625

626

627

628

13:34-42. 10.1080/15476286.2015.1128065

Ebbesen KK, Kjems J, and Hansen TB. 2016. Circular RNAs: Identification, biogenesis and function. Biochimica et Biophysica Acta (BBA) - Bioenergetics 1859:163-168. 10.1016/j.bbagrm.2015.07.007

Errichelli L, Dini Modigliani S, Laneve P, Colantoni A, Legnini I, Capauto D, Rosa A, De Santis R, Scarfo R, Peruzzi G, Lu L, Caffarelli E, Shneider NA, Morlando M, and Bozzoni I. 2017. FUS affects circular RNA expression in murine embryonic stem cell-derived motor neurons. Nat Commun 8:14741. 10.1038/ncomms14741

Fan X, Weng X, Zhao Y, Chen W, Gan T, and Xu D. 2017. Circular RNAs in Cardiovascular Disease: An Overview. Biomed Res Int 2017:5135781. 10.1155/2017/5135781

Fei T, Chen Y, Xiao T, Li W, Cato L, Zhang P, Cotter MB, Bowden M, Lis RT, Zhao SG, Wu Q, Feng FY, Loda M, He HH, Liu XS, and Brown M. 2017. Genome-wide CRISPR screen identifies HNRNPL as a prostate cancer dependency regulating RNA splicing. Proc Natl Acad Sci U S A 114:E5207e5215. 10.1073/pnas.1617467114

Fu L, Yao T, Chen Q, Mo X, Hu Y, and Guo J. 2017. Screening differential circular RNA expression profiles reveals hsa_circ_0004018 is associated with hepatocellular carcinoma. Oncotarget. 10.18632/oncotarget.16881

Gao Y, Zhang J, and Zhao F. 2017. Circular RNA identification based on multiple seed matching. Brief Bioinform. 10.1093/bib/bbx014

Geng HH, Li R, Su YM, Xiao J, Pan M, Cai XX, and Ji XP. 2016. The Circular RNA Cdr1as Promotes Myocardial Infarction by Mediating the Regulation of miR-7a on Its Target Genes Expression. PLoS One 11:e0151753. 10.1371/journal.pone.0151753

Glazar P, Papavasileiou P, and Rajewsky N. 2014. circBase: a database for circular RNAs. RNA 20:16661670. 10.1261/rna.043687.113

Guarnerio J, Bezzi M, Jeong JC, Paffenholz SV, Berry K, Naldini MM, Lo-Coco F, Tay Y, Beck AH, and Pandolfi PP. 2016. Oncogenic Role of Fusion-circRNAs Derived from Cancer-Associated Chromosomal Translocations. Cell 165:289-302. 10.1016/j.cell.2016.03.020

Guo W, Zhang J, Zhang D, Cao S, Li G, Zhang S, Wang Z, Wen P, Yang H, Shi X, Pan J, and Ye H. 2017. Polymorphisms and expression pattern of circular RNA circ-ITCH contributes to the carcinogenesis of hepatocellular carcinoma. Oncotarget. 10.18632/oncotarget.18327

Han D, Li J, Wang H, Su X, Hou J, Gu Y, Qian C, Lin Y, Liu X, Huang M, Li N, Zhou W, Yu Y, and Cao X. 2017. Circular RNA circMTO1 acts as the sponge of microRNA-9 to suppress hepatocellular carcinoma progression. Hepatology 66:1151-1164. 10.1002/hep.29270

Hancock JM. 2014. Circles within circles: commentary on Ghosal et al. (2013) "Circ2Traits: a comprehensive database for circular RNA potentially associated with disease and traits". Front Genet 5:459. 10.3389/fgene.2014.00459

Hansen TB, Jensen TI, Clausen BH, Bramsen JB, Finsen B, Damgaard CK, and Kjems J. 2013a. Natural RNA circles function as efficient microRNA sponges. Nature 495:384-388. 10.1038/nature11993

Hansen TB, Kjems J, and Damgaard CK. 2013b. Circular RNA and miR-7 in cancer. Cancer Research 73:5609-5612. 10.1158/0008-5472.can-13-1568

PeerJ reviewing PDF | (2018:03:27193:3:1:REVIEW 18 Jul 2018) 
Hansen TB, Wiklund ED, Bramsen JB, Villadsen SB, Statham AL, Clark SJ, and Kjems J. 2011. miRNAdependent gene silencing involving Ago2-mediated cleavage of a circular antisense RNA. EMBO Journal 30:4414-4422. 10.1038/emboj.2011.359

Hentze MW, and Preiss T. 2013. Circular RNAs: splicing's enigma variations. EMBO Journal 32:923-925. 10.1038/emboj.2013.53

Hoffmann S, Otto C, Doose G, Tanzer A, Langenberger D, Christ S, Kunz M, Holdt LM, Teupser D, Hackermuller J, and Stadler PF. 2014. A multi-split mapping algorithm for circular RNA, splicing, trans-splicing and fusion detection. Genome Biol 15:R34. 10.1186/gb-2014-15-2-r34

Holdt LM, Kohlmaier A, and Teupser D. 2017. Molecular roles and function of circular RNAs in eukaryotic cells. Cellular and Molecular Life Sciences.

Holdt LM, Stahringer A, Sass K, Pichler G, Kulak NA, Wilfert W, Kohlmaier A, Herbst A, Northoff BH, Nicolaou A, Gabel G, Beutner F, Scholz M, Thiery J, Musunuru K, Krohn K, Mann M, and Teupser D. 2016. Circular non-coding RNA ANRIL modulates ribosomal RNA maturation and atherosclerosis in humans. Nat Commun 7:12429. 10.1038/ncomms12429

Hsiao KY, Lin YC, Gupta SK, Chang N, Yen L, Sun HS, and Tsai SJ. 2017. Noncoding Effects of Circular RNA CCDC66 Promote Colon Cancer Growth and Metastasis. Cancer Research 77:2339-2350. 10.1158/0008-5472.can-16-1883

Huang C, Liang D, Tatomer DC, and Wilusz JE. 2018. A length-dependent evolutionarily conserved pathway controls nuclear export of circular RNAs. Genes $\mathcal{E}$ Development 32:639-644. 10.1101/gad.314856.118

Huang C, and Shan G. 2015. What happens at or after transcription: Insights into circRNA biogenesis and function. Transcription 6:61-64. 10.1080/21541264.2015.1071301

Huang G, Zhu H, Shi Y, Wu W, Cai H, and Chen X. 2015. cir-ITCH plays an inhibitory role in colorectal cancer by regulating the Wnt/beta-catenin pathway. PLoS One 10:e0131225. 10.1371/journal.pone.0131225

Huang R, Zhang Y, Han B, Bai Y, Zhou R, Gan G, Chao J, Hu G, and Yao H. 2017. Circular RNA HIPK2 regulates astrocyte activation via cooperation of autophagy and ER stress by targeting MIR1242HG. Autophagy 13:1722-1741. 10.1080/15548627.2017.1356975

Ivanov A, Memczak S, Wyler E, Torti F, Porath HT, Orejuela MR, Piechotta M, Levanon EY, Landthaler M, Dieterich C, and Rajewsky N. 2015. Analysis of intron sequences reveals hallmarks of circular RNA biogenesis in animals. Cell Rep 10:170-177. 10.1016/j.celrep.2014.12.019

Jeck WR, and Sharpless NE. 2014. Detecting and characterizing circular RNAs. Nature Biotechnology 32:453-461. 10.1038/nbt.2890

Jeck WR, Sorrentino JA, Wang K, Slevin MK, Burd CE, Liu J, Marzluff WF, and Sharpless NE. 2013. Circular RNAs are abundant, conserved, and associated with ALU repeats. RNA 19:141-157. 10.1261/rna.035667.112

Kalyana-Sundaram S, Kumar-Sinha C, Shankar S, Robinson DR, Wu YM, Cao X, Asangani IA, Kothari V, Prensner JR, Lonigro RJ, Iyer MK, Barrette T, Shanmugam A, Dhanasekaran SM, Palanisamy N, and Chinnaiyan AM. 2012. Expressed pseudogenes in the transcriptional landscape of human 
668

669

670

671

672

673

674

675

676

677

678

679

680

681

682

683

684

685

686

687

688

689

690

691

692

693

694

695

696

697

698

699

700

701

702

703

704

705

706

cancers. Cell 149:1622-1634. 10.1016/j.cell.2012.04.041

Kim MK, Shin HM, Jung H, Lee E, Kim TK, Kim TN, Kwon MJ, Lee SH, Rhee BD, and Park JH. 2017. Comparison of pancreatic beta cells and alpha cells under hyperglycemia: Inverse coupling in pAkt-FoxO1. Diabetes Res Clin Pract 131:1-11. 10.1016/j.diabres.2017.05.017

Kramer MC, Liang D, Tatomer DC, Gold B, March ZM, Cherry S, and Wilusz JE. 2015. Combinatorial control of Drosophila circular RNA expression by intronic repeats, hnRNPs, and SR proteins. Genes \& Development 29:2168-2182. 10.1101/gad.270421.115

Kumar L, Shamsuzzama, Haque R, Baghel T, and Nazir A. 2017. Circular RNAs: the Emerging Class of Non-coding RNAs and Their Potential Role in Human Neurodegenerative Diseases. Molecular Neurobiology 54:7224-7234. 10.1007/s12035-016-0213-8

Lee BY, Timpson P, Horvath LG, and Daly RJ. 2015. FAK signaling in human cancer as a target for therapeutics. Pharmacology \& Therapeutics 146:132-149. 10.1016/j.pharmthera.2014.10.001

Legnini I, Di Timoteo G, Rossi F, Morlando M, Briganti F, Sthandier O, Fatica A, Santini T, Andronache A, Wade M, Laneve P, Rajewsky N, and Bozzoni I. 2017. Circ-ZNF609 Is a Circular RNA that Can Be Translated and Functions in Myogenesis. Molecular Cell 66:22-37.e29. 10.1016/j.molcel.2017.02.017

Li B, Li R, Zhang C, Bian HJ, Wang F, Xiao J, Liu SW, Yi W, Zhang MX, Wang SX, Zhang Y, Su GH, and Ji XP. 2014a. MicroRNA-7a/b protects against cardiac myocyte injury in ischemia/reperfusion by targeting poly(ADP-ribose) polymerase. PLoS One 9:e90096. 10.1371/journal.pone.0090096

Li F, Zhang L, Li W, Deng J, Zheng J, An M, Lu J, and Zhou Y. 2015a. Circular RNA ITCH has inhibitory effect on ESCC by suppressing the Wnt/beta-catenin pathway. Oncotarget 6:6001-6013. 10.18632/oncotarget.3469

Li J, Yang J, Zhou P, Le Y, Zhou C, Wang S, Xu D, Lin HK, and Gong Z. 2015b. Circular RNAs in cancer: novel insights into origins, properties, functions and implications. Am J Cancer Res 5:472-480.

Li JH, Liu S, Zhou H, Qu LH, and Yang JH. 2014b. starBase v2.0: decoding miRNA-ceRNA, miRNAncRNA and protein-RNA interaction networks from large-scale CLIP-Seq data. Nucleic Acids Research 42:D92-97. 10.1093/nar/gkt1248

Li P, Chen S, Chen H, Mo X, Li T, Shao Y, Xiao B, and Guo J. 2015c. Using circular RNA as a novel type of biomarker in the screening of gastric cancer. Clin Chim Acta 444:132-136. 10.1016/j.cca.2015.02.018

Li S, Teng S, Xu J, Su G, Zhang Y, Zhao J, Zhang S, Wang H, Qin W, Lu ZJ, Guo Y, Zhu Q, and Wang D. 2018. Microarray is an efficient tool for circRNA profiling. Brief Bioinform.

Li X, Liu CX, Xue W, Zhang Y, Jiang S, Yin QF, Wei J, Yao RW, Yang L, and Chen LL. 2017a. Coordinated circRNA Biogenesis and Function with NF90/NF110 in Viral Infection. Molecular Cell. 10.1016/j.molcel.2017.05.023

Li Z, Huang C, Bao C, Chen L, Lin M, Wang X, Zhong G, Yu B, Hu W, Dai L, Zhu P, Chang Z, Wu Q, Zhao Y, Jia Y, Xu P, Liu H, and Shan G. 2017b. Corrigendum: Exon-intron circular RNAs regulate transcription in the nucleus. Nature Structural \& Molecular Biology 24:194. 10.1038/nsmb0217-194a

Liang D, Tatomer DC, Luo Z, Wu H, Yang L, Chen LL, Cherry S, and Wilusz JE. 2017. The Output of Protein-Coding Genes Shifts to Circular RNAs When the Pre-mRNA Processing Machinery Is Limiting. Molecular Cell 68:940-954.e943. 10.1016/j.molcel.2017.10.034 
707

708

709

710

711

712

713

714

715

716

717

718

719

720

721

722

723

724

725

726

727

728

729

730

731

732

733

734

735

736

737

738

739

740

741

742

743

744

745

Lin F, Zhao GA, Chen ZG, Wang XH, Lu FH, Zhang YC, Cai RY, Liang WQ, Li JH, Li M, Zhang GH, and Yang YM. 2018. [Network correlation of circRNA-miRNA and the possible regulatory mechanism in acute myocardial infarction]. Zhonghua Yi Xue Za Zhi 98:851-854. 10.3760/cma.j.issn.03762491.2018.11.012

Lin SP, Ye S, Long Y, Fan Y, Mao HF, Chen MT, and Ma QJ. 2016. Circular RNA expression alterations are involved in OGD/R-induced neuron injury. Biochemical and Biophysical Research Communications 471:52-56. 10.1016/j.bbrc.2016.01.183

Liu YC, Li JR, Sun CH, Andrews E, Chao RF, Lin FM, Weng SL, Hsu SD, Huang CC, Cheng C, Liu CC, and Huang HD. 2016. CircNet: a database of circular RNAs derived from transcriptome sequencing data. Nucleic Acids Research 44:D209-215. 10.1093/nar/gkv940

Lu L, Sun J, Shi P, Kong W, Xu K, He B, Zhang S, and Wang J. 2017. Identification of circular RNAs as a promising new class of diagnostic biomarkers for human breast cancer. Oncotarget. 10.18632/oncotarget.17307

Lukiw WJ. 2013. Circular RNA (circRNA) in Alzheimer's disease (AD). Front Genet 4:307. 10.3389/fgene.2013.00307

Memczak S, Jens M, Elefsinioti A, Torti F, Krueger J, Rybak A, Maier L, Mackowiak SD, Gregersen LH, Munschauer M, Loewer A, Ziebold U, Landthaler M, Kocks C, le Noble F, and Rajewsky N. 2013. Circular RNAs are a large class of animal RNAs with regulatory potency. Nature 495:333-338. 10.1038/nature11928

Mendis S, Davis S, and Norrving B. 2015. Organizational update: the world health organization global status report on noncommunicable diseases 2014; one more landmark step in the combat against stroke and vascular disease. Stroke 46:e121-122. 10.1161/strokeaha.115.008097

Meng J, Chen S, Han J, Qian B, Wang X, Zhong W, Qin Y, Zhang H, Gao W, Lei Y, Yang W, Yang L, Zhang C, Liu H, Liu Y, Zhou HG, Sun T, and Yang C. 2018. Twist1 regulates Vimentin through Cul2 circular RNA to promote EMT in hepatocellular carcinoma. Cancer Research. 10.1158/00085472.can-17-3009

Meng S, Zhou H, Feng Z, Xu Z, Tang Y, Li P, and Wu M. 2017. CircRNA: functions and properties of a novel potential biomarker for cancer. Mol Cancer 16:94. 10.1186/s12943-017-0663-2

Metge F, Czaja-Hasse LF, Reinhardt R, and Dieterich C. 2017. FUCHS-towards full circular RNA characterization using RNAseq. PeerJ 5:e2934. 10.7717/peer.2934

Morris KV, and Mattick JS. 2014. The rise of regulatory RNA. Nature Reviews: Genetics 15:423-437. 10.1038/nrg3722

Mozaffarian D, Benjamin EJ, Go AS, Arnett DK, Blaha MJ, Cushman M, de Ferranti S, Despres JP, Fullerton HJ, Howard VJ, Huffman MD, Judd SE, Kissela BM, Lackland DT, Lichtman JH, Lisabeth LD, Liu S, Mackey RH, Matchar DB, McGuire DK, Mohler ER, 3rd, Moy CS, Muntner P, Mussolino ME, Nasir K, Neumar RW, Nichol G, Palaniappan L, Pandey DK, Reeves MJ, Rodriguez CJ, Sorlie PD, Stein J, Towfighi A, Turan TN, Virani SS, Willey JZ, Woo D, Yeh RW, and Turner MB. 2015. Heart disease and stroke statistics--2015 update: a report from the American Heart Association. Circulation 131:e29-322. 10.1161/cir.0000000000000152 
746

747

748

749

750

751

752

753

754

755

756

757

758

759

760

761

762

763

764

765

766

767

768

769

770

771

772

773

774

775

776

777

778

779

780

781

782

783

784

Nan A, Chen L, Zhang N, Liu Z, Yang T, Wang Z, Yang C, and Jiang Y. 2017. A novel regulatory network among LncRpa, CircRar1, MiR-671 and apoptotic genes promotes lead-induced neuronal cell apoptosis. Archives of Toxicology 91:1671-1684. 10.1007/s00204-016-1837-1

Pamudurti NR, Bartok O, Jens M, Ashwal-Fluss R, Stottmeister C, Ruhe L, Hanan M, Wyler E, PerezHernandez D, Ramberger E, Shenzis S, Samson M, Dittmar G, Landthaler M, Chekulaeva M, Rajewsky N, and Kadener S. 2017. Translation of CircRNAs. Molecular Cell 66:9-21.e27. 10.1016/j.molcel.2017.02.021

Panda AC, and Gorospe M. 2018. Detection and Analysis of Circular RNAs by RT-PCR. Bio Protoc 8.

Peng J, Sheng W, Huang D, Venook AP, Xu Y, Guan Z, and Cai S. 2011. Perineural invasion in pT3N0 rectal cancer: the incidence and its prognostic effect. Cancer 117:1415-1421. 10.1002/cncr.25620

Peng L, Yuan XQ, and Li GC. 2015. The emerging landscape of circular RNA ciRS-7 in cancer (Review). Oncology Reports 33:2669-2674. 10.3892/or.2015.3904

Piwecka M, Glazar P, Hernandez-Miranda LR, Memczak S, Wolf SA, Rybak-Wolf A, Filipchyk A, Klironomos F, Cerda Jara CA, Fenske P, Trimbuch T, Zywitza V, Plass M, Schreyer L, Ayoub S, Kocks C, Kuhn R, Rosenmund C, Birchmeier C, and Rajewsky N. 2017. Loss of a mammalian circular RNA locus causes miRNA deregulation and affects brain function. Science 357. 10.1126/science.aam8526

Qin M, Liu G, Huo X, Tao X, Sun X, Ge Z, Yang J, Fan J, Liu L, and Qin W. 2016. Hsa_circ_0001649: A circular RNA and potential novel biomarker for hepatocellular carcinoma. Cancer Biomark 16:161169. $10.3233 / \mathrm{cbm}-150552$

Qu S, Yang X, Li X, Wang J, Gao Y, Shang R, Sun W, Dou K, and Li H. 2015. Circular RNA: A new star of noncoding RNAs. Cancer Letters 365:141-148. 10.1016/j.canlet.2015.06.003

Read DE, Gupta A, Ladilov Y, Samali A, and Gupta S. 2014. miRNA signature of unfolded protein response in H9c2 rat cardiomyoblasts. Cell Biosci 4:56. 10.1186/2045-3701-4-56

Rodriguez-Trelles F, Tarrio R, and Ayala FJ. 2006. Origins and evolution of spliceosomal introns. Annual Review of Genetics 40:47-76. 10.1146/annurev.genet.40.110405.090625

Rybak-Wolf A, Stottmeister C, Glazar P, Jens M, Pino N, Giusti S, Hanan M, Behm M, Bartok O, AshwalFluss R, Herzog M, Schreyer L, Papavasileiou P, Ivanov A, Ohman M, Refojo D, Kadener S, and Rajewsky N. 2015. Circular RNAs in the Mammalian Brain Are Highly Abundant, Conserved, and Dynamically Expressed. Molecular Cell 58:870-885. 10.1016/j.molcel.2015.03.027

Salzman J, Chen RE, Olsen MN, Wang PL, and Brown PO. 2013. Cell-type specific features of circular RNA expression. PLoS Genetics 9:e1003777. 10.1371/journal.pgen.1003777

Salzman J, Gawad C, Wang PL, Lacayo N, and Brown PO. 2012. Circular RNAs are the predominant transcript isoform from hundreds of human genes in diverse cell types. PLoS One 7:e30733. 10.1371/journal.pone.0030733

Shang X, Li G, Liu H, Li T, Liu J, Zhao Q, and Wang C. 2016. Comprehensive Circular RNA Profiling Reveals That hsa_circ_0005075, a New Circular RNA Biomarker, Is Involved in Hepatocellular Crcinoma Development. Medicine (Baltimore) 95:e3811. 10.1097/md.0000000000003811

Shao Y, Chen L, Lu R, Zhang X, Xiao B, Ye G, and Guo J. 2017. Decreased expression of hsa_circ_0001895 
785

786

787

788

789

790

791

792

793

794

795

796

797

798

799

800

801

802

803

804

805

806

807

808

809

810

811

812

813

814

815

816

817

818

819

820

821

822

823

in human gastric cancer and its clinical significances. Tumour Biol 39:1010428317699125. $10.1177 / 1010428317699125$

Shi L, Yan P, Liang Y, Sun Y, Shen J, Zhou S, Lin H, Liang X, and Cai X. 2017. Circular RNA expression is suppressed by androgen receptor (AR)-regulated adenosine deaminase that acts on RNA (ADAR1) in human hepatocellular carcinoma. Cell Death Dis 8:e3171. 10.1038/cddis.2017.556

Sui W, Shi Z, Xue W, Ou M, Zhu Y, Chen J, Lin H, Liu F, and Dai Y. 2017. Circular RNA and gene expression profiles in gastric cancer based on microarray chip technology. Oncology Reports 37:1804-1814. 10.3892/or.2017.5415

Suzuki H, and Tsukahara T. 2014. A view of pre-mRNA splicing from RNase R resistant RNAs. Int J Mol Sci 15:9331-9342. 10.3390/ijms15069331

Suzuki H, Zuo Y, Wang J, Zhang MQ, Malhotra A, and Mayeda A. 2006. Characterization of RNase Rdigested cellular RNA source that consists of lariat and circular RNAs from pre-mRNA splicing. Nucleic Acids Research 34:e63. 10.1093/nar/gk1151

Tabak HF, Van der Horst G, Smit J, Winter AJ, Mul Y, and Groot Koerkamp MJ. 1988. Discrimination between RNA circles, interlocked RNA circles and lariats using two-dimensional polyacrylamide gel electrophoresis. Nucleic Acids Research 16:6597-6605.

Tay ML, and Pek JW. 2017. Maternally Inherited Stable Intronic Sequence RNA Triggers a SelfReinforcing Feedback Loop during Development. Current Biology 27:1062-1067. 10.1016/j.cub.2017.02.040

Thompson SR. 2012. So you want to know if your message has an IRES? Wiley Interdiscip Rev RNA 3:697705. 10.1002/wrna.1129

Tian M, Chen R, Li T, and Xiao B. 2017. Reduced expression of circRNA hsa_circ_0003159 in gastric cancer and its clinical significance. J Clin Lab Anal. 10.1002/jcla.22281

Vausort M, Salgado-Somoza A, Zhang L, Leszek P, Scholz M, Teren A, Burkhardt R, Thiery J, Wagner DR, and Devaux Y. 2016. Myocardial Infarction-Associated Circular RNA Predicting Left Ventricular Dysfunction. Journal of the American College of Cardiology 68:1247-1248. 10.1016/j.jacc.2016.06.040

Wang K, Gan TY, Li N, Liu CY, Zhou LY, Gao JN, Chen C, Yan KW, Ponnusamy M, Zhang YH, and Li PF. 2017a. Circular RNA mediates cardiomyocyte death via miRNA-dependent upregulation of MTP18 expression. Cell Death and Differentiation 24:1111-1120. 10.1038/cdd.2017.61

Wang K, Long B, Liu F, Wang JX, Liu CY, Zhao B, Zhou LY, Sun T, Wang M, Yu T, Gong Y, Liu J, Dong YH, Li N, and Li PF. 2016. A circular RNA protects the heart from pathological hypertrophy and heart failure by targeting miR-223. Eur Heart J 37:2602-2611. 10.1093/eurheartj/ehv713

Wang PL, Bao Y, Yee MC, Barrett SP, Hogan GJ, Olsen MN, Dinneny JR, Brown PO, and Salzman J. 2014. Circular RNA is expressed across the eukaryotic tree of life. PLoS One 9:e90859. 10.1371/journal.pone.0090859

Wang X, Zhang Y, Huang L, Zhang J, Pan F, Li B, Yan Y, Jia B, Liu H, Li S, and Zheng W. 2015a. Decreased expression of hsa_circ_001988 in colorectal cancer and its clinical significances. Int J Clin Exp Pathol 8:16020-16025.

Wang Y, Liu J, Liu C, Naji A, and Stoffers DA. 2013. MicroRNA-7 regulates the mTOR pathway and 
proliferation in adult pancreatic beta-cells. Diabetes 62:887-895. 10.2337/db12-0451

Wang Y, Mo Y, Gong Z, Yang X, Yang M, Zhang S, Xiong F, Xiang B, Zhou M, Liao Q, Zhang W, Li X, Li X, Li Y, Li G, Zeng Z, and Xiong W. 2017b. Circular RNAs in human cancer. Mol Cancer 16:25. 10.1186/s12943-017-0598-7

Wang Y, and Wang Z. 2015. Efficient backsplicing produces translatable circular mRNAs. RNA 21:172-179. 10.1261/rna.048272.114

Wang YS, Zhou J, Hong K, Cheng XS, and Li YG. 2015b. MicroRNA-223 displays a protective role against cardiomyocyte hypertrophy by targeting cardiac troponin I-interacting kinase. Cell Physiol Biochem 35:1546-1556. 10.1159/000373970

Westholm JO, Miura P, Olson S, Shenker S, Joseph B, Sanfilippo P, Celniker SE, Graveley BR, and Lai EC. 2014. Genome-wide analysis of drosophila circular RNAs reveals their structural and sequence properties and age-dependent neural accumulation. Cell Rep 9:1966-1980. 10.1016/j.celrep.2014.10.062

Wilusz JE, and Sharp PA. 2013. Molecular biology. A circuitous route to noncoding RNA. Science 340:440441. 10.1126/science.1238522

Wu J, Jiang Z, Chen C, Hu Q, Fu Z, Chen J, Wang Z, Wang Q, Li A, Marks JR, Guo C, Chen Y, Zhou J, Yang L, Lin C, and Wang S. 2018a. CircIRAK3 sponges miR-3607 to facilitate breast cancer metastasis. Cancer Letters 430:179-192. 10.1016/j.canlet.2018.05.033

Wu SM, Liu H, Huang PJ, Chang IY, Lee CC, Yang CY, Tsai WS, and Tan BC. 2018b. circlncRNAnet: an integrated web-based resource for mapping functional networks of long or circular forms of noncoding RNAs. Gigascience 7:1-10. 10.1093/gigascience/gix118

Wu Y, Zhang Y, Zhang Y, and Wang JJ. 2017. CircRNA hsa_circ_0005105 up regulates NAMPT expression and promotes chondrocyte extracellular matrix degradation by sponging miR-26a. Cell Biology International. 10.1002/cbin.10761

Xia S, Feng J, Lei L, Hu J, Xia L, Wang J, Xiang Y, Liu L, Zhong S, Han L, and He C. $2016 a$. Comprehensive characterization of tissue-specific circular RNAs in the human and mouse genomes. Brief Bioinform. 10.1093/bib/bbw081

Xia W, Qiu M, Chen R, Wang S, Leng X, Wang J, Xu Y, Hu J, Dong G, Xu PL, and Yin R. 2016b. Circular RNA has_circ_0067934 is upregulated in esophageal squamous cell carcinoma and promoted proliferation. Sci Rep 6:35576. 10.1038/srep35576

Xie H, Ren X, Xin S, Lan X, Lu G, Lin Y, Yang S, Zeng Z, Liao W, Ding YQ, and Liang L. 2016. Emerging roles of circRNA_001569 targeting miR-145 in the proliferation and invasion of colorectal cancer. Oncotarget 7:26680-26691. 10.18632/oncotarget.8589

Xu H, Guo S, Li W, and Yu P. 2015. The circular RNA Cdr1as, via miR-7 and its targets, regulates insulin transcription and secretion in islet cells. Sci Rep 5:12453. 10.1038/srep12453

Xu L, Zhang M, Zheng X, Yi P, Lan C, and Xu M. 2017a. The circular RNA ciRS-7 (Cdr1as) acts as a risk factor of hepatic microvascular invasion in hepatocellular carcinoma. Journal of Cancer Research and Clinical Oncology 143:17-27. 10.1007/s00432-016-2256-7

Xu XW, Zheng BA, Hu ZM, Qian ZY, Huang CJ, Liu XQ, and Wu WD. 2017b. Circular RNA 
863

864

865

866

867

868

869

870

871

872

873

874

875

876

877

878

879

880

881

882

883

884

885

886

887

888

889

890

891

892

893

894

895

896

897

898

899

900

901

hsa_circ_000984 promotes colon cancer growth and metastasis by sponging miR-106b. Oncotarget 8:91674-91683. 10.18632/oncotarget.21748

Xu ZQ, Yang MG, Liu HJ, and Su CQ. 2017c. Circular RNA hsa_circ_0003221 (circPTK2) promotes the proliferation and migration of bladder cancer cells. Journal of Cellular Biochemistry. $10.1002 / j c b .26492$

Yang C, Wu D, Gao L, Liu X, Jin Y, Wang D, Wang T, and Li X. 2016. Competing endogenous RNA networks in human cancer: hypothesis, validation, and perspectives. Oncotarget 7:13479-13490. 10.18632/oncotarget.7266

Yang L, Han B, Zhang Y, Bai Y, Chao J, Hu G, and Yao H. 2018a. Engagement of circular RNA HECW2 in the nonautophagic role of ATG5 implicated in the endothelial-mesenchymal transition. Autophagy:1-15. 10.1080/15548627.2017.1414755

Yang Q, Du WW, Wu N, Yang W, Awan FM, Fang L, Ma J, Li X, Zeng Y, Yang Z, Dong J, Khorshidi A, and Yang BB. 2017a. A circular RNA promotes tumorigenesis by inducing c-myc nuclear translocation. Cell Death and Differentiation. 10.1038/cdd.2017.86

Yang Y, Fan X, Mao M, Song X, Wu P, Zhang Y, Jin Y, Yang Y, Chen LL, Wang Y, Wong CC, Xiao X, and Wang Z. 2017b. Extensive translation of circular RNAs driven by N6-methyladenosine. Cell Research 27:626-641. 10.1038/cr.2017.31

Yang Y, Gao X, Zhang M, Yan S, Sun C, Xiao F, Huang N, Yang X, Zhao K, Zhou H, Huang S, Xie B, and Zhang N. 2018b. Novel Role of FBXW7 Circular RNA in Repressing Glioma Tumorigenesis. Journal of the National Cancer Institute 110. 10.1093/jnci/djx166

Yao Z, Luo J, Hu K, Lin J, Huang H, Wang Q, Zhang P, Xiong Z, He C, Huang Z, Liu B, and Yang Y. 2017. ZKSCAN1 gene and its related circular RNA (circZKSCAN1) both inhibit hepatocellular carcinoma cell growth, migration, and invasion but through different signaling pathways. Mol Oncol. 10.1002/1878-0261.12045

You X, and Conrad TO. 2016. Acfs: accurate circRNA identification and quantification from RNA-Seq data. Sci Rep 6:38820. 10.1038/srep38820

You X, Vlatkovic I, Babic A, Will T, Epstein I, Tushev G, Akbalik G, Wang M, Glock C, Quedenau C, Wang X, Hou J, Liu H, Sun W, Sambandan S, Chen T, Schuman EM, and Chen W. 2015. Neural circular RNAs are derived from synaptic genes and regulated by development and plasticity. Nature Neuroscience 18:603-610. 10.1038/nn.3975

Zhang XO, Dong R, Zhang Y, Zhang JL, Luo Z, Zhang J, Chen LL, and Yang L. 2016. Diverse alternative back-splicing and alternative splicing landscape of circular RNAs. Genome Research 26:1277-1287. 10.1101/gr.202895.115

Zhang XO, Wang HB, Zhang Y, Lu X, Chen LL, and Yang L. 2014. Complementary sequence-mediated exon circularization. Cell 159:134-147. 10.1016/j.cell.2014.09.001

Zhang Y, Liu H, Li W, Yu J, Li J, Shen Z, Ye G, Qi X, and Li G. 2017. CircRNA_100269 is downregulated in gastric cancer and suppresses tumor cell growth by targeting miR-630. Aging (Albany NY). 10.18632/aging.101254

Zhang Y, Zhang XO, Chen T, Xiang JF, Yin QF, Xing YH, Zhu S, Yang L, and Chen LL. 2013. Circular 
902 intronic long noncoding RNAs. Molecular Cell 51:792-806. 10.1016/j.molcel.2013.08.017

903 Zhao Y, Alexandrov PN, Jaber V, and Lukiw WJ. 2016. Deficiency in the Ubiquitin Conjugating Enzyme

904

905

906

907

908

909

910

911

912

913

914

915

916

917

918

919

920

921

922

923

924

925 UBE2A in Alzheimer's Disease (AD) is Linked to Deficits in a Natural Circular miRNA-7 Sponge (circRNA; ciRS-7). Genes (Basel) 7. 10.3390/genes7120116

Zhao YJ, Wang JH, Fu B, Ma MX, Li BX, Huang Q, and Yang BF. 2009. Effects of 3-aminobenzamide on expressions of poly (ADP ribose) polymerase and apoptosis inducing factor in cardiomyocytes of rats with acute myocardial infarction. Chin Med J (Engl) 122:1322-1327.

Zhao Z, Li X, Jian D, Hao P, Rao L, and Li M. 2017. Hsa_circ_0054633 in peripheral blood can be used as a diagnostic biomarker of pre-diabetes and type 2 diabetes mellitus. Acta Diabetol 54:237-245. 10.1007/s00592-016-0943-0

Zhao ZJ, and Shen J. 2015. Circular RNA participates in the carcinogenesis and the malignant behavior of cancer. RNA Biol:1-8. 10.1080/15476286.2015.1122162

Zheng LL, Li JH, Wu J, Sun WJ, Liu S, Wang ZL, Zhou H, Yang JH, and Qu LH. 2016. deepBase v2.0: identification, expression, evolution and function of small RNAs, LncRNAs and circular RNAs from deep-sequencing data. Nucleic Acids Research 44:D196-202. 10.1093/nar/gkv1273

Zhong Z, Lv M, and Chen J. 2016. Screening differential circular RNA expression profiles reveals the regulatory role of circTCF25-miR-103a-3p/miR-107-CDK6 pathway in bladder carcinoma. Sci Rep 6:30919. 10.1038/srep30919

Zhou Z, Jiang R, Yang X, Guo H, Fang S, Zhang Y, Cheng Y, Wang J, Yao H, and Chao J. 2018. circRNA Mediates Silica-Induced Macrophage Activation Via HECTD1/ZC3H12A-Dependent Ubiquitination. Theranostics 8:575-592. 10.7150/thno.21648

Zhu X, Wang X, Wei S, Chen Y, Chen Y, Fan X, Han S, and Wu G. 2017. hsa_circ_0013958: a circular RNA and potential novel biomarker for lung adenocarcinoma. FEBS Journal. 10.1111/febs.14132 


\section{Table 1 (on next page)}

The characteristics of different types of CircRNA

ecRNA : Exon circRNA ; ciRNA : Intron circRNA ; ElciRNA : Exon-intron circRNA 
1

Table 1 Characteristics of different circRNA types

\begin{tabular}{|c|c|c|c|c|c|}
\hline Name & Type & Location & Joint Site & $\begin{array}{l}\text { Sequence } \\
\text { Feature }\end{array}$ & Function \\
\hline $\begin{array}{l}\text { EcRNA(Zhan } \\
\text { g et al. 2014) }\end{array}$ & exon & cytoplasms & $\begin{array}{l}3^{\prime}-5^{\prime} \\
\text { phosphodi } \\
\text { ester bond }\end{array}$ & $\begin{array}{l}\text { Formed by } \\
\text { cyclization of } \\
\text { exons } \\
\text { containing the } \\
\text { reverse } \\
\text { complementar } \\
\text { y sequence of } \\
\text { introns and } \\
\text { selective } \\
\text { cyclization. }\end{array}$ & $\begin{array}{l}\text { Functioning } \\
\text { as miRNA } \\
\text { sponges; } \\
\text { Interact with } \\
\text { RNA-binding } \\
\text { proteins } \\
\text { (RBPs); } \\
\text { Participates in } \\
\text { translation. }\end{array}$ \\
\hline $\begin{array}{l}\text { CiRNA(Zhang } \\
\text { et al. 2013) }\end{array}$ & intron & nucleus & $\begin{array}{l}\text { 2'-5' } \\
\text { phosphodi } \\
\text { ester bond }\end{array}$ & $\begin{array}{l}\text { 5' splice site } \\
\text { enriched with } 7 \\
\text { GU motifs and } \\
\text { 3' branch site } \\
\text { contains } 11 \mathrm{C} \\
\text { motifs. }\end{array}$ & $\begin{array}{l}\text { Regulation of } \\
\text { gene } \\
\text { transcription. }\end{array}$ \\
\hline $\begin{array}{l}\text { ElciRNA(Li et } \\
\text { al. 2017b) }\end{array}$ & $\begin{array}{l}\text { exon - } \\
\text { intron }\end{array}$ & nucleus & $\begin{array}{l}\text { 3'-5' } \\
\text { phosphodi } \\
\text { ester bond }\end{array}$ & $\begin{array}{l}\text { Formed by } \\
\text { cyclization of } \\
\text { exons } \\
\text { containing the } \\
\text { reverse } \\
\text { complementar } \\
\text { y sequence of } \\
\text { introns and } \\
\text { selective } \\
\text { cyclization. }\end{array}$ & $\begin{array}{l}\text { Regulation of } \\
\text { gene } \\
\text { transcription. }\end{array}$ \\
\hline
\end{tabular}




\section{Table 2 (on next page)}

CircRNA in disease development and progression 
Table 2 Database for CircRNA Research

\begin{tabular}{|c|c|c|c|}
\hline Tool Name & $\begin{array}{l}\text { The latest } \\
\text { version }\end{array}$ & URL & Remarks \\
\hline $\begin{array}{l}\text { circlncRNAnet( } \\
\text { Wu et al. } \\
\text { 2018b) }\end{array}$ & May 2017 & $\begin{array}{l}\text { http://app.cgu.edu.tw/circl } \\
\text { nc/ }\end{array}$ & $\begin{array}{l}\text { It aims to broaden the } \\
\text { understanding of ncRNA } \\
\text { candidates by testing in silico } \\
\text { several hypotheses of ncRNA- } \\
\text { based functions on the basis of } \\
\text { large-scale RNA-seq data. }\end{array}$ \\
\hline $\begin{array}{l}\text { starBase v2. } \\
\text { 0(Li et al. } \\
\text { 2014b) }\end{array}$ & $\begin{array}{l}\text { December } \\
2013\end{array}$ & $\begin{array}{l}\text { http://starbase. sysu. edu. } \\
\text { cn/ }\end{array}$ & $\begin{array}{l}\text { Includes microRNA, mRNA, } \\
\text { IncRNA and other RNA } \\
\text { information. It is a useful tool } \\
\text { for detecting miRNA-circRNA } \\
\text { interaction. If there is a need to } \\
\text { retrieve all circRNA in the } \\
\text { genome, circRNABase is useful. }\end{array}$ \\
\hline $\begin{array}{l}\text { circBase(Glazar } \\
\text { et al. 2014) }\end{array}$ & $\begin{array}{l}\text { December } \\
2015\end{array}$ & http://www. circbase. org/ & $\begin{array}{l}\text { Thousands of circRNAs are } \\
\text { annotated from eukaryotic cells. }\end{array}$ \\
\hline $\begin{array}{l}\text { circ2Traits(Han } \\
\text { cock 2014) }\end{array}$ & $\begin{array}{l}\text { December } \\
2013\end{array}$ & $\begin{array}{l}\text { http://gyanxet-beta. } \\
\text { com/circdb }\end{array}$ & $\begin{array}{l}\text { Provides more information } \\
\text { about the genomic positions of }\end{array}$ \\
\hline $\begin{array}{l}\text { nc2Cancer(Che } \\
\text { ng et al. 2015) }\end{array}$ & & $\begin{array}{l}\text { http://www. Bioinfo. } \\
\text { Tsinghua. Edu. cn/nc2Cance }\end{array}$ & $\begin{array}{l}\text { circRNAs and circRNA- } \\
\text { associated diseases. }\end{array}$ \\
\hline $\begin{array}{l}\text { CircNet(Liu et } \\
\text { al. 2016) }\end{array}$ & $\begin{array}{l}\text { December } \\
2015\end{array}$ & $\begin{array}{l}\text { http://circnet. mbc. nctu. } \\
\text { edu. tw/ }\end{array}$ & $\begin{array}{l}\text { A database of circular RNAs } \\
\text { derived from transcriptome } \\
\text { sequencing data, and this tool } \\
\text { provides the most circRNA } \\
\text { annotation, in particular, from } \\
\text { human. }\end{array}$ \\
\hline $\begin{array}{l}\text { DeepBase v2. } \\
\text { O(Zheng et al. } \\
\text { 2016) }\end{array}$ & $\begin{array}{l}\text { November } \\
2015\end{array}$ & $\begin{array}{l}\text { http://biocenter. sysu. edu. } \\
\text { cn/deepBase/ }\end{array}$ & $\begin{array}{l}\text { This database is a platform for } \\
\text { annotation and discovery of } \\
\text { small (microRNA, siRNA and } \\
\text { piRNA) and long ncRNAs from } \\
\text { next-generation sequencing } \\
\text { data. }\end{array}$ \\
\hline $\begin{array}{l}\text { Circlnteractom } \\
\text { e(Dudekula et } \\
\text { al. 2016) }\end{array}$ & $\begin{array}{l}\text { December } \\
2015\end{array}$ & $\begin{array}{l}\text { http://circinteractome. nia. } \\
\text { nih. gov/ }\end{array}$ & $\begin{array}{l}\text { This database can be used only } \\
\text { to match the circRNA with } \\
\text { relevant RNA-binding proteins. }\end{array}$ \\
\hline $\begin{array}{l}\text { TSCD(Xia et al. } \\
\text { 2016a) }\end{array}$ & $\begin{array}{l}\text { August } \\
2016\end{array}$ & $\begin{array}{l}\text { http://gb. whu. edu. } \\
\text { cn/TSCD/ }\end{array}$ & $\begin{array}{l}\text { It is useful for characterizing } \\
\text { tissue-specific circRNAs in } \\
\text { human and mouse genomes. }\end{array}$ \\
\hline $\begin{array}{l}\text { CIRCpedia } \\
\text { (Zhang et al. } \\
\text { 2016) }\end{array}$ & $\begin{array}{l}\text { January } \\
2015\end{array}$ & $\begin{array}{l}\text { http://www. picb. ac. } \\
\text { cn/rnomics/circpedia/ }\end{array}$ & $\begin{array}{l}\text { This database contains reverse } \\
\text { splicing and variable splicing } \\
\text { sites of circRNAs from } 39 \\
\text { individuals and mouse samples. }\end{array}$ \\
\hline
\end{tabular}




$\begin{array}{lll}\text { circRNADb(Che } & \text { http://reprod. njmu. edu. } & \text { It contains a record of more } \\ \text { n et al. 2016) } & \text { th/circrnadb } & \begin{array}{l}\text { nan } 30,000 \text { exons with circRNA } \\ \text { nature in the human genome }\end{array}\end{array}$

2 Every database present has its own sphere of competence, and only the perfect combination of various databases can provide accurate information. 


\section{Table 3 (on next page)}

Database for circRNA research

Every database present has its own sphere of competence, only the perfect combination of various database s can provide information accurate. 
1

Table 3 CircRNA in disease development and progression

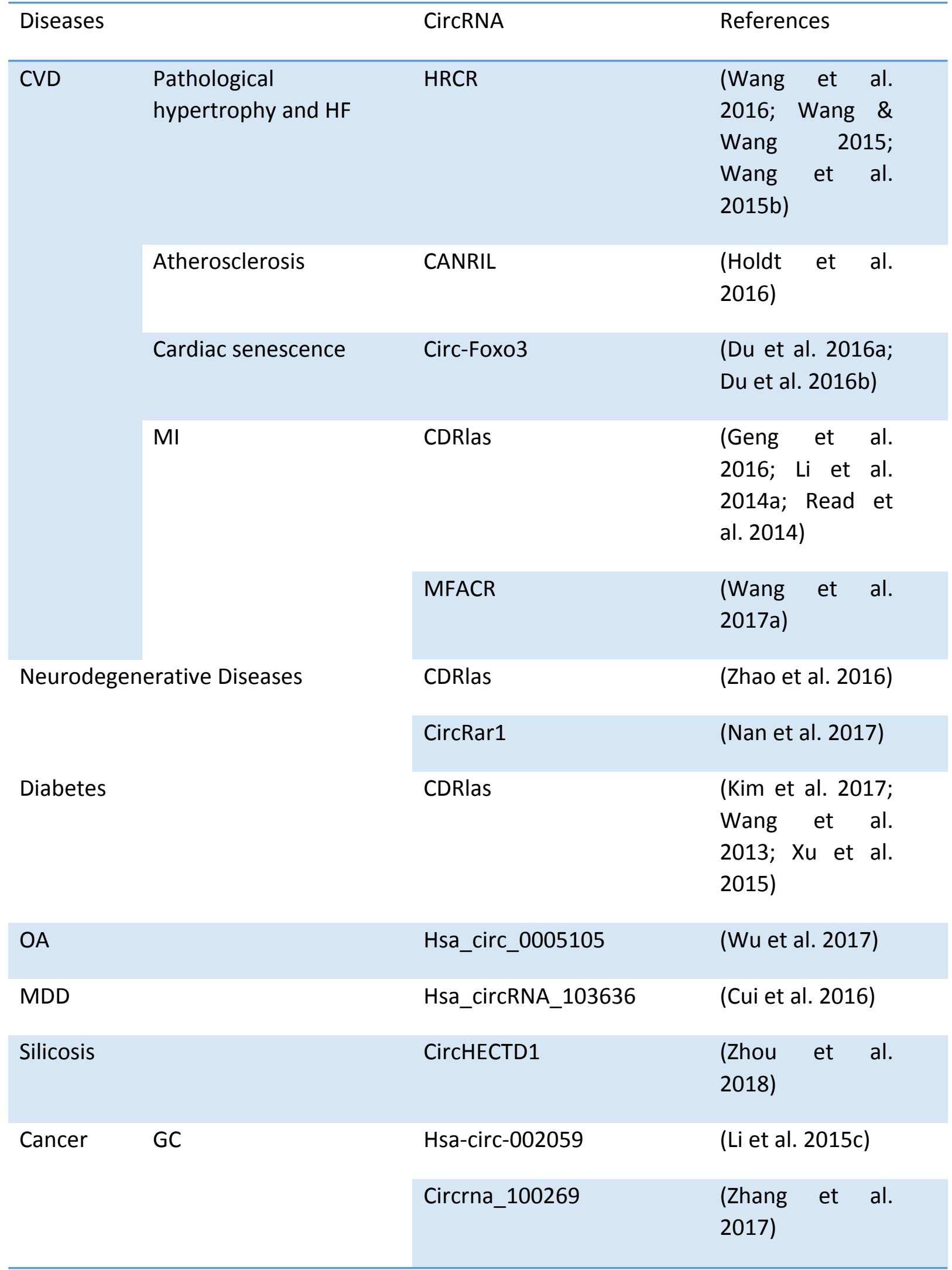




\begin{tabular}{|c|c|c|}
\hline & Hsa_circ_0003159 & (Tian et al. 2017) \\
\hline & Hsa_circ_0000190 & $\begin{array}{l}\text { (Chen et al. } \\
2017 c)\end{array}$ \\
\hline & CircPVT1 & $\begin{array}{l}\text { (Chen et al. } \\
2017 a)\end{array}$ \\
\hline \multirow[t]{4}{*}{ CRC } & Hsa_circ_001988 & $\begin{array}{l}\text { (Wang et al. } \\
2015 a)\end{array}$ \\
\hline & Circ_001569 & (Xie et al. 2016) \\
\hline & CircCCDC66 & $\begin{array}{l}\text { (Hsiao et al. } \\
\text { 2017) }\end{array}$ \\
\hline & Hsa_circ_000984 & (Xu et al. 2017b) \\
\hline \multirow[t]{2}{*}{ ESCC } & Has_circ_0067934 & (Xia et al. 2016b) \\
\hline & Cir-ITCH & (Li et al. 2015a) \\
\hline \multirow[t]{8}{*}{$\mathrm{HCC}$} & CircZKSCAN1 & (Yao et al. 2017) \\
\hline & CDRlas & (Xu et al. 2017a) \\
\hline & Hsa_circ_0005075 & $\begin{array}{l}\text { (Shang et al. } \\
2016)\end{array}$ \\
\hline & Hsa_circ_0004018 & (Fu et al. 2017) \\
\hline & Hsa_circ_0001649 & (Qin et al. 2016) \\
\hline & CircARSP91 & (Shi et al. 2017) \\
\hline & Circ-10720 & $\begin{array}{l}\text { (Meng et al. } \\
2018 \text { ) }\end{array}$ \\
\hline & Circ-ITCH & (Guo et al. 2017) \\
\hline Cervical Cancer & CDRlas & (Lee et al. 2015) \\
\hline $\mathrm{BC}$ & Circ-Amotl1 & $\begin{array}{l}\text { (Yang et al. } \\
2017 a)\end{array}$ \\
\hline
\end{tabular}




\begin{tabular}{lll}
\hline $\begin{array}{l}\text { Human } \\
\text { squamous } \begin{array}{r}\text { oral } \\
\text { carcinomas (OSCC). }\end{array}\end{array}$ & Circrna_100290 & $\begin{array}{l}\text { (Chen et } \\
\text { 2017b) }\end{array}$ \\
$\begin{array}{l}\text { Lung } \\
\text { adenocarcinoma } \\
\text { (LAC) }\end{array}$ & Hsa_circ_0013958 & (Zhu et al. 2017) \\
$\begin{array}{l}\text { Bladder carcinoma } \\
\text { CircTCF25 }\end{array}$ & $\begin{array}{l}\text { (Zhong et al. } \\
\text { 2016) }\end{array}$ \\
& CircPTK2 & (Xu et al. 2017c)
\end{tabular}

2 
Figure 1

Characteristics of different types of circRNA

A

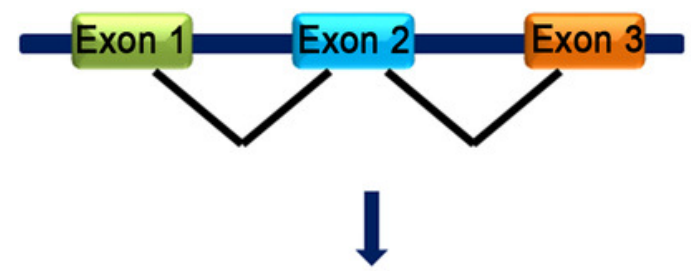

Exon 1 Exon 2 Exon $3 \triangle A A A$ mRNA

C

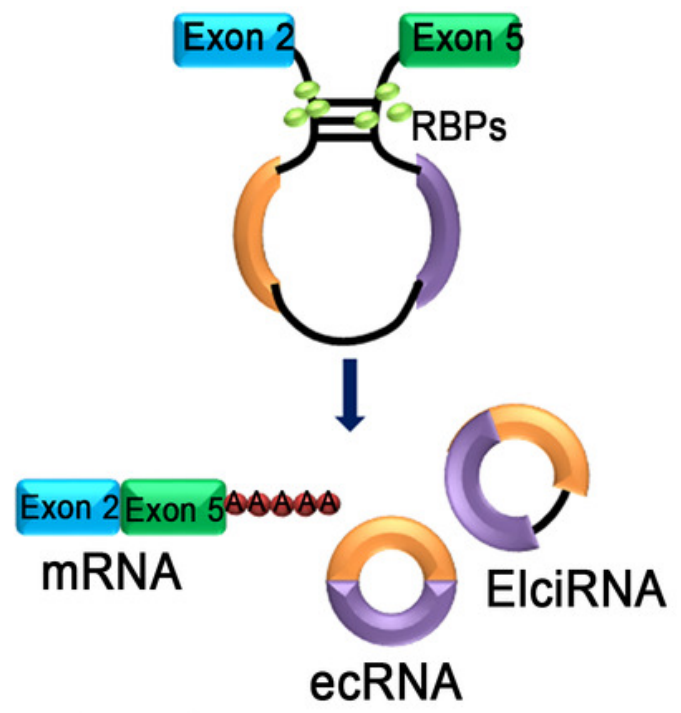

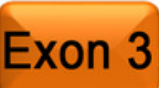

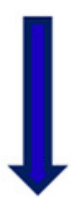

B

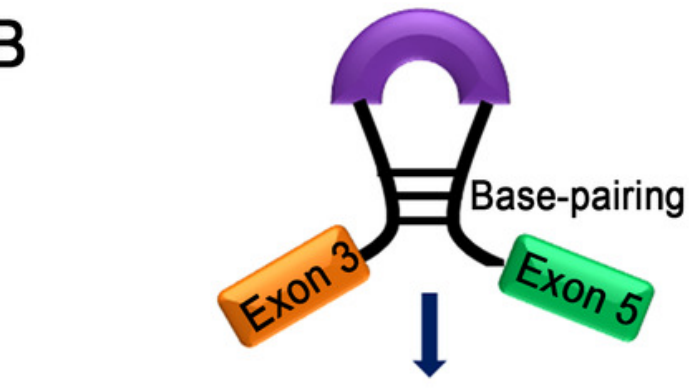

Exon 3Exon $5 \triangle A A A$ mRNA

D

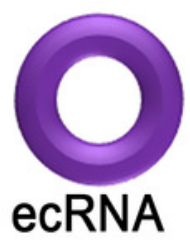

Exon 3 Exon 4 AAAAB mRNA 


\section{Figure 2}

\section{Two different models of exon circularization of circRNA}

(A) intron-pairing-driven circularization : during the formation of circRNA, an intron reverse complementary motif comprising GU-rich and C-rich elements is the key component to facilitate cyclization. (B) lariat-driven circularization : t he formation of circRNA is facilitated by the lariat structure. The complementary ALU flanking element which is repeated in the intron region competing for classical linear RNA splicing and the circularization is accelerated by reverse complementarity.

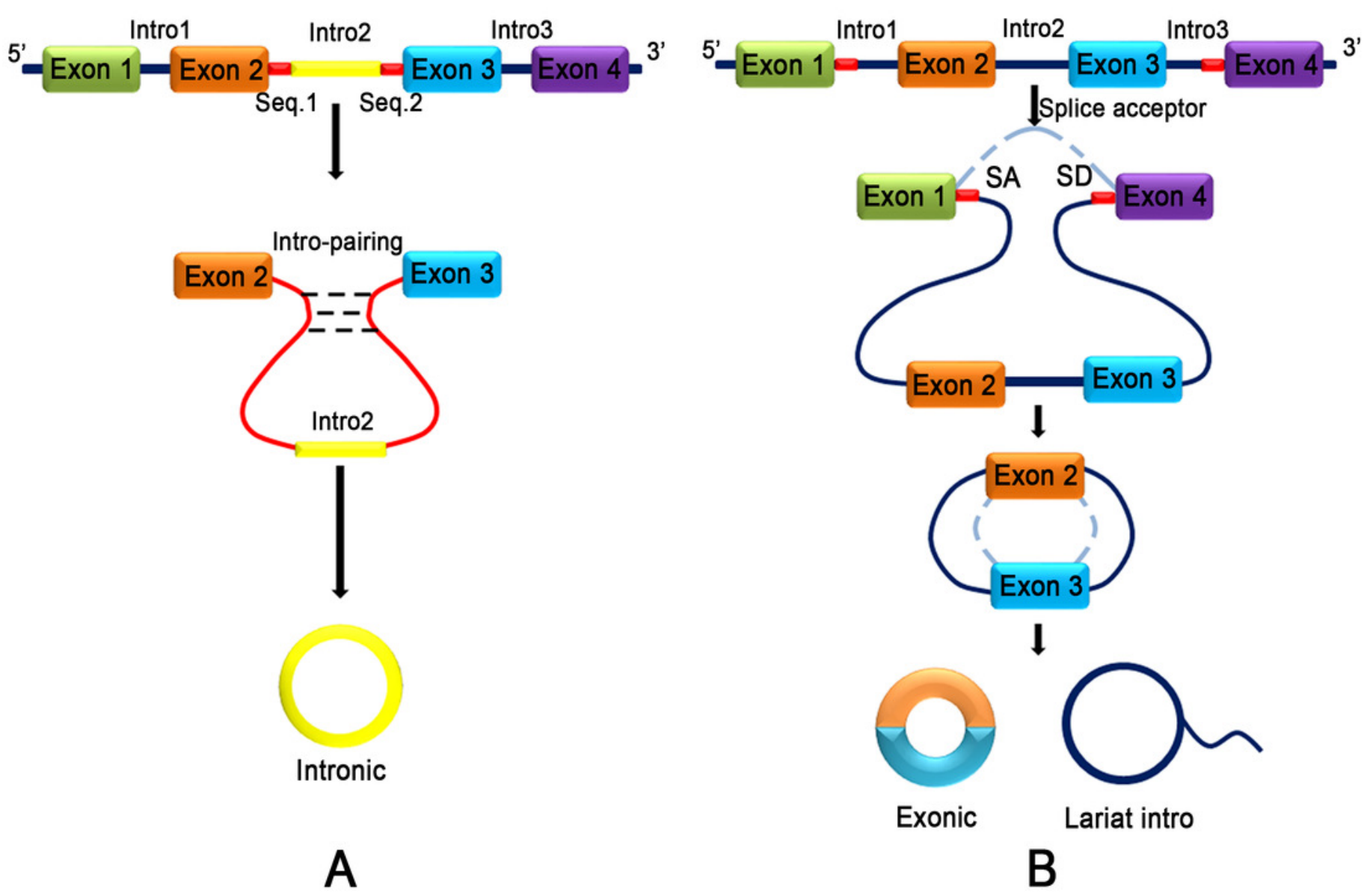




\section{Figure 3}

The five main functions of the circRNA

(A) Regulating selective splicing or transcription: Stable circRNA and ElciRNAs are located in the nucleus, where they bind to RNA polymerase and promoting transcription; circRNA competes with pre-mRNA splicing to reduce the level of linear mRNA and excludes specificity from pre-mRNA by changing the composition of processed mRNA; (B) Interaction with RBPs: circRNA binds with RBPs and ribonucleoprotein complexes and interfere with their functions. As a single circRNA can bind with multiple units of RBPs, they serve as stores of RBPs; (C) miRNA sponging activity: circRNA binds with miRNA and affecting the miRNA dependent target gene suppression; (D) Rolling Circle Translation: Some circRNA can be translated into proteins by means of a roll loop amplification mechanism; (E) Generation of Pseudogenes: Some circRNA are reverse transcribed into CDNA and integrated into the genome, however, the mechanism of integration is not yet clear.

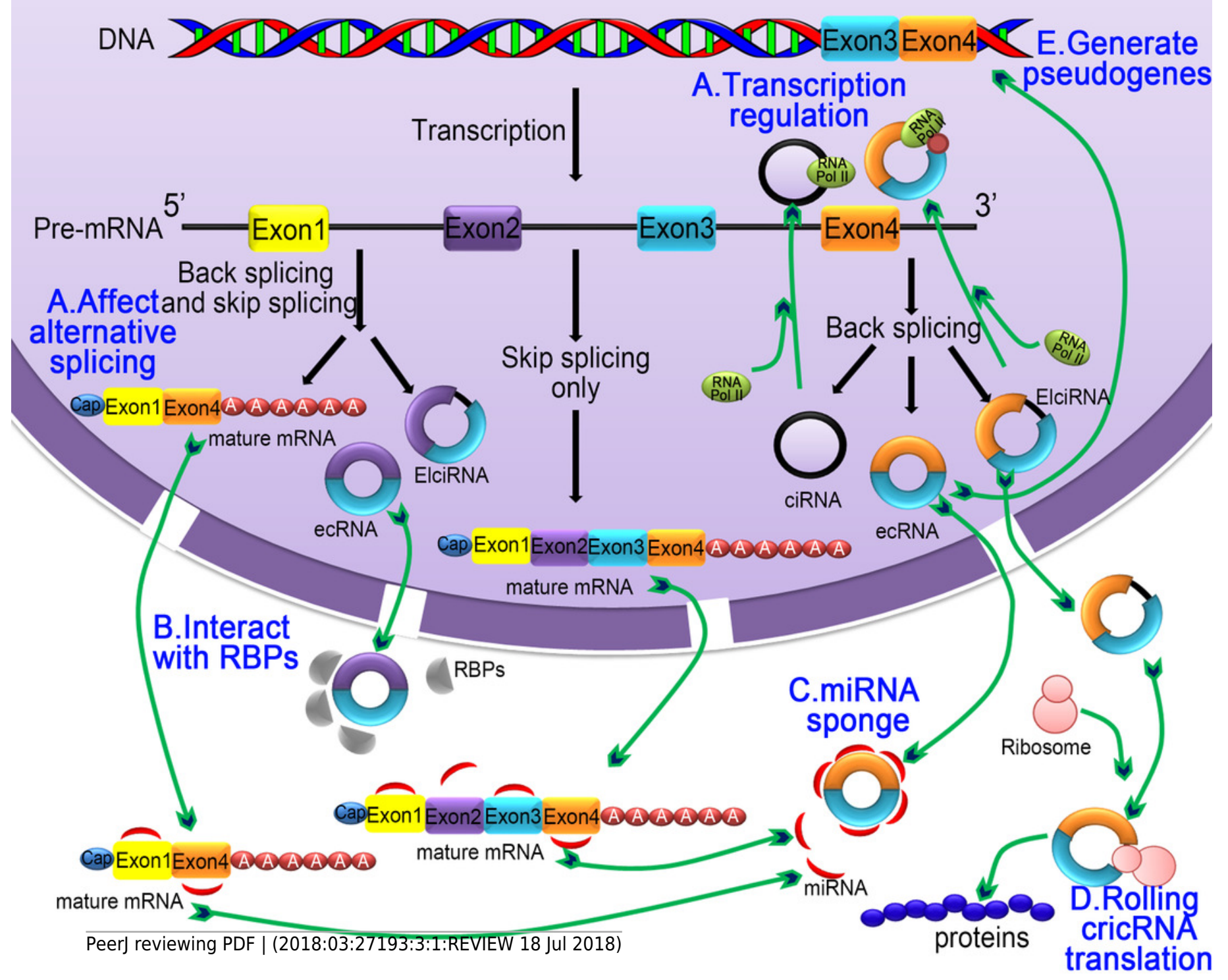




\section{Figure 4}

The difference between linear RNA and circRNA primer design

(A) FW is a forward primer with $b$ chain as template. The base sequence of synthesis is the original sequence of $a ; R V$ is a reverse primer with a chain as template, and the base sequence of synthesis is the original sequence of $\mathrm{b}$, The sequence between $\mathrm{FW}$ and $\mathrm{RV}$ is high; (B) Need to reverse the original primers: The synthetic primers are FW' and RV', where FW' is the reverse complementary sequence of the RV primer, $\mathrm{RV}^{\prime}$ is the reverse complementary sequence of FW primer.

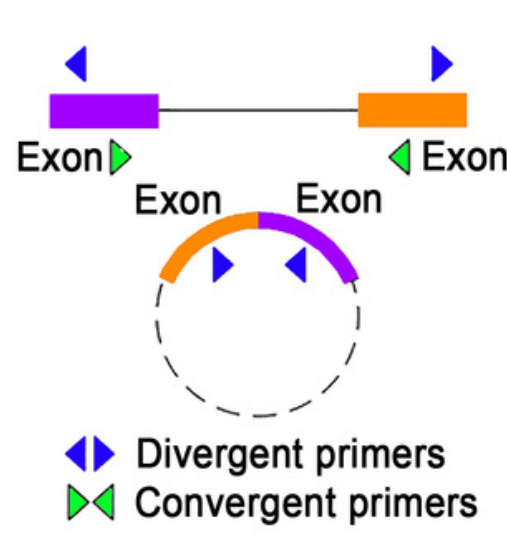

Design principle

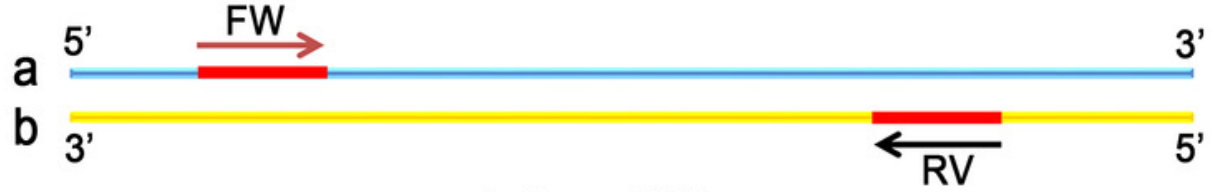

A. linear RNA

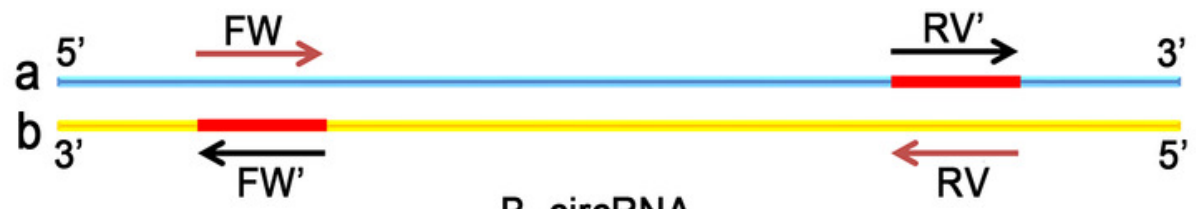

B. circRNA

Design illustrations 